\title{
The prosody of rhetorical questions in English ${ }^{1}$
}

\author{
NICOLE DEHÉ and BETTINA BRAUN \\ Universität Konstanz
}

(Received 12 June 2018; revised 20 December 2018)

\begin{abstract}
This article contributes to our knowledge about the prosodic realisation of rhetorical questions (RQs) as compared to information-seeking questions (ISQs). It reports on a production experiment testing the prosody of English wh- and polar RQs and ISQs in a Canadian variety. In previous literature, the contribution of prosody to the distinction between the two illocution types has often been limited to the intonational realisation of the terminus of the utterance, i.e. whether it ends in a rise or a fall. Along with edge tones, we tested other phonological and phonetic parameters. Our results are as follows: (i) The intonational terminus was distinctive only for polar questions (rise vs plateau), not for wh-questions (low throughout). (ii) Moreover, the semantic difference between RQs and ISQs is signalled by pitch accents. It is reflected in nuclear pitch accent type for wh-questions, and accent type and position for polar questions. (iii) Phonetically, RQs are produced with longer constituent durations and - for $w h$-questions - a softer voice quality in the $w h$-word. Taken together, several intonational categories and phonetic parameters contribute to the distinction between RQs and ISQs. A simple distinction between rising and falling intonation is in any case insufficient.
\end{abstract}

Keywords: rhetorical questions, prosody, question intonation, illocution type, question type

\section{Introduction}

This article investigates the prosodic differences between English information-seeking questions on the one hand and surface-syntactically identical rhetorical questions on the other. We study both wh-questions (1) and polar questions (2).

(1) Wh-question

Who likes roses?

(2) Polar question

Does anyone like roses?

Prototypical questions perform the directive speech act of requesting information. Here we refer to questions that perform this act as information-seeking questions (henceforth ISQs). ${ }^{2}$ Polar questions 'request an answer that specifies whether the proposition expressed by their sentence radical holds or does not hold' (Krifka 2011: 1747), i.e. the expected answer may be 'yes’ or ‘no' (Karttunen 1977; Groenendijk \& Stokhof 1984).

\footnotetext{
${ }^{1}$ We thank Angela James, Stephanie Gustedt and Clara Huttenlauch for help with the construction of the materials and data annotation, Anja Arnhold for data collection, and María Biezma for discussion. The research presented here was funded by the DFG as part of research unit 'Questions at the Interfaces' (FOR 2111, project P6), grant numbers DE 876/3-1 and BR 3428/4-1.

2 In addition to or instead of seeking information, utterances with interrogative syntax may serve other functions, among them initiating repair, requesting confirmation or offering (Krifka 2011).
} 
Semantically, polar questions hence denote the set of possible answers (or resolutions) $\{\mathrm{p}, \neg \mathrm{p}\}$; but see Biezma \& Rawlins (2012). Wh-questions, on the other hand, 'create an open proposition by leaving parts of the description of the proposition unspecified' (Krifka 2011: 1744); in English, the open parameter is represented by the wh-pronoun. The expected answer is one that provides information about the open parameter. Semantically, a wh-question is represented either as a set of propositions that would constitute felicitous answers (Hamblin 1973; Karttunen 1977; Groenendijk \& Stokhof 1984) or as an incomplete expression (e.g. Hausser \& Zaefferer 1979; von Stechow \& Zimmermann 1984).

Rhetorical questions (henceforth RQs) are formally (i.e. surface-syntactically) interrogatives, but differ from ISQs in discourse function. In particular, according to Biezma \& Rawlins (2017) and based on much previous literature, they have the following three characteristics: (i) RQs do not expect an answer (Hudson 1975; Quirk et al. 1985; Wilson \& Sperber 1988; Ilie 1995; Banuazizi \& Cresswell 1999); (ii) RQs have the feel of an assertion (Sadock 1971; Quirk et al. 1985; Gutiérrez Rexach 1998; Han 2002; Rohde 2006); and (iii) RQs do not have to but can optionally be answered (Rohde 2006; Caponigro \& Sprouse 2007). These characteristics are related: if RQs have the force (or the feel) of assertions, then the speaker does not request an answer; however, since RQs are formally questions, an answer is still possible. In a corpus study, Rohde (2006) finds that answers to RQs are overwhelmingly confirmations and backchannels, while answers to ISQs are predominantly yes/no-responses (to polar questions) or statements (to $w$ h-questions), suggesting that RQs 'do not function ... like regular questions but instead express an opinion' to which the addressee may react (Rohde 2006: 143). This fits in with Biezma \& Rawlins' (2017) observation that RQs are often used to 'extract a commitment to the rhetorical point' from an interlocutor. Also, while for ISQs there is a high degree of uncertainty as to the answer on the part of the speaker, for RQs there is no uncertainty. Instead, the answer is in the common ground and obvious to all interlocutors (Rohde 2006; Caponigro \& Sprouse 2007; Biezma \& Rawlins 2017) or is intended to be added to the common ground (Biezma \& Rawlins 2017). Biezma \& Rawlins (2017) further argue that for a question to be interpreted as an RQ, it 'must conventionally indicate the speaker's attitude ... that the question they are asking is non-inquisitive in context'.

It is a common assumption that in cases of identical surface syntax of ISQs and RQs, prosodic parameters help cue their interpretation (Gutiérrez Rexach 1998; Biezma \& Rawlins 2017). However, the exact difference in the prosody of ISQs vs RQs often remains unspecified, prosodic parameters have been said to be 'hard to pin down' (Biezma \& Rawlins 2017: 306, 313) and the prosody of RQs has not been studied to the same extent as the prosody of ISQs. The goal of the present article is to fill this gap, i.e. to establish the prosodic realisation of RQs in production and compare it to the prosody of ISQs. The article thus makes a substantial contribution to our knowledge of the meaning of interrogative utterances and their prosodic realisation, and thus our knowledge about exact prosodic means to convey illocution type. In the remainder of the introduction, we will outline relevant previous claims and findings in the literature 
on the prosodic realisation of questions in English, divided by question type ( $w h$ vs polar), starting with wh-questions. Based mainly on findings for other illocution types and for the prosody of RQs in German, we then briefly discuss possible differences in phonetic realisation between RQs and ISQs. Our hypotheses will be based on these previous findings.

\subsection{Phonology}

In the relevant semantic and phonological literature on question intonation, different phonological frameworks are used to describe intonational patterns. Some authors use the terminology of the British framework, such as fall-rise, high rise, fall (e.g. Schubiger 1958; Quirk et al. 1985; Banuazizi \& Creswell 1999; Han 2002), others use symbols from the ToBI annotation system couched in Autosegmental-Metrical Phonology, such as $\mathrm{H}^{*}, \mathrm{H}-, \mathrm{L} \%$ and combinations thereof (e.g. Pierrehumbert \& Hirschberg 1990; Bartels 1999), others use both (e.g. Hedberg \& Sosa 2002; Hedberg et al. 2004; Hedberg et al. 2010; Hedberg et al. 2017). The primitives in the British School can to some extent be translated into combinations of pitch accents, phrase accents and boundary tones (e.g. a fall-rise corresponds to $\mathrm{H}^{*} \mathrm{~L}-\mathrm{H} \%$ or $\mathrm{H}^{*}+\mathrm{L} \mathrm{H}-\mathrm{H} \%$, a fall to $\mathrm{H}^{*} \mathrm{~L}-\mathrm{L} \%$, a rise-fall to $\mathrm{L}+\mathrm{H}^{*} \mathrm{~L}-\mathrm{L} \%$ or $\mathrm{L}^{*}+\mathrm{H} \mathrm{L}-\mathrm{L} \%$, etc.; see Ladd 2008: 91 for a table and critical discussion, as well as Gussenhoven 2016 for a critical discussion of ToBI in comparison with alternative systems). However, the literature varies on the use of these correspondences. For example, a fall is often equated with just the combination of phrase accent and boundary tone (L-L\%) or even just the phrase accent (L-, H-) or the boundary tone L\%. In what follows, we stick to ToBI for Mainstream American English (henceforth MAE_ToBI; Silverman et al. 1992; Beckman \& Ayers 1997; Beckman et al. 2005) in the annotation of our data and use descriptive terminology borrowed from the British framework where appropriate (e.g. where referring to relevant literature that uses it or to allow for cross-linguistic comparison). At the right edge of the utterance, we refer to $\mathrm{L}-$ and $\mathrm{H}$ - as phrase accents, to just $\mathrm{L} \%$ and $\mathrm{H} \%$ as boundary tone, and to the combinations of phrase accent and boundary tone as edge tones. Three of four possible edge tones occurred in the data: a final fall to a low point in the speaker's range ( $\mathrm{L}-\mathrm{L} \%)$, a final rise $(\mathrm{H}-\mathrm{H} \%)$, where $\mathrm{H} \%$ is upstepped by $\mathrm{H}$-, i.e. higher compared to the preceding $\mathrm{H}$ - phrase accent, and a final mid-level plateau ( $\mathrm{H}-\mathrm{L} \%)$, where $\mathrm{L} \%$ is upstepped by the preceding $\mathrm{H}$ - phrase accent, i.e. where $\mathrm{L} \%$ does not represent a low point in the speaker's f0 range. ${ }^{3}$ We use the term (overall) tune associated with an utterance for the sequence of all tonal events in

\footnotetext{
3 Note that the MAE_ToBI annotation conventions (Beckman \& Ayers 1997: 18; Beckman \& Hirschberg n.d.) differ from those in related frameworks, such as GToBI (German ToBI; Grice \& Baumann 2002; Grice et al. 2005), where $\mathrm{H}-{ }^{\wedge} \mathrm{H} \%$ corresponds to MAE_ToBI H-H\%, and H- $\%$ corresponds to MAE_ToBI H-L\%. Crucially, in MAE_ToBI, $\mathrm{H}-\mathrm{L} \%$ is used for a final mid-level plateau. The assumption is that the $\mathrm{H}$ - phrase accent upsteps $\mathrm{L} \%$ to a value in the middle of the speaker's range, and $\mathrm{L} \%$ is therefore higher than $\mathrm{L} \%$ in $\mathrm{L}-\mathrm{L} \%$, and lower than the upstepped $\mathrm{H} \%$ boundary tone in $\mathrm{H}-\mathrm{H} \%$.
} 
one utterance, i.e. prenuclear accent, nuclear accent and edge tone. This is different from nuclear tune, which would only comprise the nuclear accent and edge tone.

\subsubsection{Wh-questions}

Information-seeking $w h$-questions in English are generally assumed to be realised with a nuclear high fall (Schubiger 1958; Pierrehumbert \& Hirschberg 1990; Bartels 1999; Hedberg \& Sosa 2002; Hedberg et al. 2010), i.e. H* L-L\% in autosegmental-metrical phonology. Note that this holds for read as well as spontaneous speech, as shown by Hedberg \& Sosa's (2002) corpus data from natural discourse. Hedberg \& Sosa (2002) also find that the $w h$-word almost always has a prenuclear accent, which in their data is typically $\mathrm{L}^{*}+\mathrm{H}$.

Rhetorical $w h$-RQs, on the other hand, are claimed to be realised with a rise-fall, 'less commonly a simple falling tone' (Quirk et al. 1985: 826). In her theoretical study, Han (2002) assumes for $w h$-questions 'that the intonational contour serves as a cue that a $w h$-question is a rhetorical question that expresses an assertion' (Han 2002: 217). Since Han also assumes that 'a declarative sentence expressing an assertion' has 'a falling intonation' (Han 2002: 215), we may safely infer that she assumes $w h$-RQs to have falling intonation, too. However, since $w h$-ISQs are also falling, this would not distinguish ISQs from RQs. So while Han seems to advocate an intonational distinction between (assertive) RQs and (non-assertive) ISQ, for wh-questions it is not clear what this difference would be. According to Bartels (1999: ch. 8.2), wh-RQs, like polar RQs, may have either rising or falling intonation, but the reasoning is different for the two question types. For wh-questions, she argues, non-tonal cues (e.g. the context) are responsible for interrogative utterances to be interpreted as questions or statements, i.e. in wh-questions (unlike in polar questions, see below) 'L- does not necessarily indicate non-questionhood' (Bartels 1999: 257; italics in original). Factors affecting the intonation of $w h$-questions according to Bartels include politeness strategies (see also Banuazizi \& Cresswell 1999) and didactic stratagems.

\subsubsection{Polar questions}

According to previous studies, English polar ISQs are phonologically predominantly realised with a low rise (Schubiger 1958; Pierrehumbert \& Hirschberg 1990; Bartels 1999; Hedberg et al. 2010; Hedberg \& Sosa 2002), L* H-H\%. Moreover, the high rise $\left(\mathrm{H}^{*} \mathrm{H}-\mathrm{H} \%\right.$ ) can frequently be found with polar ISQs in English (e.g. Bartels 1999; Hedberg et al. 2017). It is worth mentioning that in their analysis of spontaneous speech based on data from two spoken language corpora of North American English, Hedberg et al. (2017) found 90.1 per cent rises $(\mathrm{N}=373$, total: $\mathrm{N}=410)$; of these, a total of $\mathrm{N}=327$ ( 80 per cent) were low rises, $\mathrm{N}=44$ (11 per cent) were high rises, and $\mathrm{N}=2$ (0.5 per cent) were fall-rises. We refer the reader to Hedberg et al. (2017) for a discussion of the meaning of these and the remaining contours.

The prosodic realisation is less clear for polar RQs. In their standard English grammar, Quirk et al. (1985: 826) maintain that polar RQs 'have the normal rising intonation of a yes-no question, and are distinguished chiefly by the range of pitch movement', although 
they do not base their claim on actual prosodic data or in fact say whether RQs have a wider or narrower pitch range than ISQs. Based on her assumption that RQs have the illocutionary force of an assertion, and likewise without providing empirical evidence, Han (2002) assumes the opposite. Specifically, she maintains that polar RQs have the intonational contour of an assertion, and are thus realised with falling intonation, like declaratives expressing assertions, but unlike polar ISQs. Banuazizi \& Cresswell (1999) investigate the intonation of polar questions based on data taken from the Switchboard corpus of telephone conversations. Initially, they extracted 3789 utterances of the syntactic type polar question from the Switchboard corpus. They analysed a total of 102 polar RQs and 2106 polar ISQs. Of the 102 RQs, 45 (44.1 per cent) were falls and 57 (55.9 per cent) were rises, compared with 89.7 per cent of rises for polar ISQs. Banuazizi \& Cresswell (1999) link the default intonational rise in 'genuine' polar questions to the sincerity conditions that they must meet. RQs, they argue, violate these conditions. In particular, in the speaker's mind, the answer to an $\mathrm{RQ}$ is 'either perfectly obvious or perfectly obviously knowable'. An answer is therefore not required or expected to an RQ, and there is therefore no need for an intonational rise. This explains the higher frequency of final falls with polar RQs than with polar ISQs in their corpus data (44.1 vs 10.3 per cent), but it does not explain the high percentage of rises with RQs (55.9 per cent). According to Bartels (1999: ch. 8.2), whose study is mostly based on fictive data, polar RQs may be rising or falling, depending on polarity (positive vs negative sentence radical) and speaker commitment to the proposition. ${ }^{4}$ Specifically, in her examples, H-H\% cues the 'speaker's commitment to the polar opposite of [the surface] proposition', whereas L-L\% cues assertiveness (Bartels 1999: 252f.).

In sum, the assumption that the difference between English ISQs and RQs that are string-identical at the surface is cued by intonation seems uncontroversial. In the semantic literature (e.g. Han 2002), the focus is generally on the intonational realisation of the final part of the utterance, i.e. (rise to) high $(\mathrm{H}-, \mathrm{H} \%, \mathrm{H}-\mathrm{H} \%$ ) vs (fall to) low (L-, L\%, L-L\%), but assumptions diverge as to the exact realisation of the terminus. At the same time, we know from experimental prosodic literature that utterance-final intonation is not the only phonological cue signaling the speech act conveyed by an utterance. Most importantly, recent work on the prosody of RQs in German (Braun et al. 2018) has shown that along with edge tones, pitch accents signal the difference between RQs and ISQs. Irrespective of question type, RQs were mainly realised with an $\mathrm{L}^{*}+\mathrm{H}$ nuclear accent, while polar ISQs were mostly realised with $\mathrm{L}^{*}$ and $w h$-ISQs with $\mathrm{L}+\mathrm{H}^{*}$. In addition, while prenuclear accents were not very frequent in Braun et al.'s data, if present, they contributed to the distinction between illocution types. Against this background, we hypothesise that edge tones, nuclear and prenuclear accents all contribute to the phonological distinction between ISQs and RQs in English.

\footnotetext{
4 Bartels (1999: 13) explains that 'most of [her] examples are fictive', i.e. either based on her own 'or other speakers' spontaneous intuitions ... or taken from illustrations of American English intonation contours in the literature, which tend to rely on constructed examples in turn'.
} 


\subsection{Phonetic parameters}

There is ample evidence in the literature that along with phonological cues, phonetic parameters may contribute to the disambiguation between illocution types. For example, the literature on the prosodic realisation of different speech acts suggests that phonetic parameters such as voice quality, duration and pitch height/scaling may play a role. Based on the analysis of a number of typologically diverse languages ( $¥ \bar{A}$ khoe Hail|om, Danish, Dutch, North American English, Italian, Japanese, Korean, Lao, Tzeltal, Yélî-Dnye), Sicoli et al. (2015) show that in 'questions designed to solicit agreement with an evaluation rather than information, pitch was divergent from a speaker's median predictably in the top $10 \%$ of a speaker's range' (Sicoli et al. 2015: 204). It is worth mentioning that according to Sicoli et al. (2015), evaluative questions include syntactically interrogative assessments along with RQs. Higher initial pitch in special questions ties in with findings by Heuven et al. (1999), which show that Dutch declarative questions start with a higher prenuclear pitch than string-identical declarative statements (cf. Petrone \& Niebuhr 2014 for similar results in German). However, in a direct comparison between ISQs and RQs, Braun et al. (2018) did not find differences with regard to initial pitch for either wh- or polar questions. Instead, differences were found between question types ( $w h$ vs polar). Other researchers have argued that duration signals illocution type, for example the difference between declarative questions and declaratives. Specifically, questions are produced with a faster speaking rate than statements in German, Manado Malay, Orkney English and Dutch (e.g. Heuven \& Zanten 2005; Niebuhr et al. 2010; Niebuhr 2013). If this is the case, then it is conceivable that duration also contributes to the prosodic profile of RQs. RQs, unlike ISQs, have been argued to have assertive force, thus we expect ISQs to be produced with faster speaking rate (shorter durations) than RQs. Longer constituent durations in RQs than in ISQs have indeed been reported for German (Braun et al. 2018) and for Icelandic (Dehé et al. 2018).

Along with duration, voice quality seems to differ for declarative questions and declarative statements, at least in German. For instance, Niebuhr et al. (2010) report breathier voice quality for declarative questions compared to declarative statements in German. Breathiness has also been associated with questionhood in a number of African languages (Rialland 2009). On the other hand, Braun et al. (2018) report breathier voice quality for RQs than for ISQs in German. Schourup (1985) shows for English that exasperated attitude is sometimes expressed by means of breathy voice quality. The contexts used in our production experiment that are set up to trigger rhetorical question readings establish a certain fact as self-evident. These contexts may hence also result in an exasperated attitude and thus trigger breathy voice. Against this background, we hypothesise that the phonetic parameters of initial pitch, duration and voice quality contribute to the distinction between RQs and ISQs in English. 


\subsection{Hypotheses}

What is missing in the literature on English is a systematic prosodic (phonological and phonetic) comparison between string-identical ISQs and RQs. One aim of this article is to fill this gap, i.e. to thoroughly investigate the prosodic realisation of English RQs in direct comparison to ISQs and enhance our knowledge about the exact prosodic means to convey illocution type in English. To this end, a production experiment was carried out, which is reported on in section 2. For this purpose, and based on the literature surveyed above, we set up the hypotheses given in (3). It is another aim to relate the results to previous theoretical claims in the literature (see the discussion in section 3). Our results will thus make an important contribution to the discussion of the semantic/ pragmatic differences between the two illocution types and the relationship between prosody and meaning.

(3) Hypotheses

H: ISQs and RQs differ in their prosodic realisation.

$\mathrm{H} 1$ : In phonology, all tonal parameters, i.e. edge tones as well as nuclear and prenuclear pitch accents, contribute to the distinction between ISQs and RQs.

$\mathrm{H} 2$ : In phonetics, duration, voice quality and initial pitch contribute to the distinction between ISQs and RQs.

\section{Production experiment}

\subsection{Methods}

\subsubsection{Materials}

We constructed 21 pairs of $w h$ - and polar questions (e.g. Who eats Limburger? Does anyone eat Limburger?), as well as accompanying contexts (one context triggering an information-seeking, one a rhetorical interpretation, for each question pair), similar to the German context-question pairs used in Braun et al. (2018). ${ }^{5}$ Each question was felicitous in both an information-seeking context and a rhetorical one, resulting in 21 quadruples, such as the one exemplified in tables 1 and 2. Contexts were created based on the literature about the function of and the answers to regular vs rhetorical questions (Rohde 2006; Caponigro \& Sprouse 2007; Biezma \& Rawlins 2017 in particular). Specifically, in ISQ contexts, the answer is obviously not known to the speaker and would therefore be highly informative. The short introductory description of the context situation was therefore followed by a sentence starting You would like to know or similar; see tables 1 and 2, left-hand columns). In RQ contexts, on the other hand, there is no uncertainty about the answer. On the contrary, the answer to the RQ is obvious from the given context, i.e. common ground in the imaginary situation. The contexts in the right-hand columns in tables 1 and 2 therefore include a sentence

\footnotetext{
5 The English version of the experiment is based on a similar experiment carried out for German; see Braun et al. (2018). For the German version, the context-question pairs were pretested: participants read the context-question pairs and had to indicate whether or not they contained a rhetorical question.
} 
Table 1. Contexts and target polar interrogatives

\begin{tabular}{ll}
\hline \hline Context for ISQ & Context for RQ \\
\hline $\begin{array}{c}\text { At a garden party, you offer canapés with } \\
\text { Limburger cheese. You would like to know } \\
\text { which of the guests eat this and whether they }\end{array}$ & $\begin{array}{c}\text { Your friend offers his guests a cheese tray, } \\
\text { including Limburger. However, it is well } \\
\text { known that none of your friends like stinky } \\
\text { want some of it or not. You say to the guests: }\end{array}$ \\
$\begin{array}{ll}\text { cheese and therefore nobody will touch it. } \\
\text { You say to your friend: }\end{array}$ \\
\hline \hline
\end{tabular}

Target Q: Does anyone eat Limburger?

Table 2. Contexts and target wh-interrogatives

\begin{tabular}{ll}
\hline \hline Context for ISQ & Context for RQ \\
\hline At a garden party, you offer canapés with & $\begin{array}{l}\text { Your friend offers his guests a cheese tray, } \\
\text { including Limburger. However, it is well } \\
\text { Limburger cheese. You would like to know } \\
\text { which of the guests eat this and want some of } \\
\text { it. You say to the guests: }\end{array}$ \\
& $\begin{array}{l}\text { known that none of your friends like stinky } \\
\text { cheese and therefore nobody will touch it. } \\
\text { You say to your friend: }\end{array}$ \\
\hline \hline
\end{tabular}

Target Q: Who eats Limburger?

starting However, it is well known that. A possible answer to the polar ISQ Does anyone eat Limburger? would be 'yes' or 'no', with optional additional information in case of a positive answer; for the polar RQ, the obvious answer would be the assertion of the opposite of the proposition of the question, i.e. No (nobody does). Similarly, a possible answer to the wh-ISQ Who eats Limburger? would fill the position opened by Who in the question, while the obvious answer to the same questions as wh-RQ would be Nobody (does).

The syntactic object of all target questions (e.g. Limburger in tables 1 and 2) was lexically given in all contexts to avoid effects of information structure on the prosodic realisation. All $w h$-questions started with the $w h$-word who, all polar questions included the indefinite subject pronoun anyone. All questions were constructed with positive polarity in the sentence radical.

In addition to the target items, 28 fillers were created. They were $11 w h$-exclamatives (e.g. How crazy he is!), 11 verb-first exclamatives (e.g. Has Benni grown!), three polar questions (e.g. Does he have a PhD?), two declarative sentences with exclamation mark (e.g. The farmer just hit his donkey!), and one declarative without exclamation mark (Clara is chasing the teenager with the camera.). As for the target items, contexts were created for all filler items.

\subsubsection{Procedure}

Two basic experimental lists were constructed. Each list contained both polar and wh-questions, and both illocution types. The members of the quadruplets were 
distributed across the two lists such that one list contained eleven polar and ten wh-questions, the other one 10 polar and 11 wh-questions. Illocution type was thus manipulated within-subjects. The same polar or wh-question occurred twice in each list, one in an ISQ context, the other in a RQ context. For example, the items in table 1 were members of List 1, the items in table 2 appeared in List 2. The 28 filler items were added to each list. The experimental lists were randomised for each participant separately with the constraint that two readings of a question were separated by at least four other trials. Each experiment started with four familiarisation trials to familiarise participants with the task. There was a short break after the four familiarisation trials, during which participants were allowed to ask questions, if anything was unclear. The experiment was controlled using the software Presentation (Neurobehavioral-Systems 2000). The experiment was self-paced. Each trial started with the visual display of the context, which the participant had to read silently. After a button press, the question appeared on the screen. It had to be produced aloud. The recording started simultaneously with the appearance of the question on screen. Participants pressed a button to proceed to the next trial. The recording was stopped at this point. Participants were allowed to repeat the question in case of mistakes. The whole experiment lasted about 25 to 30 minutes. The participants were asked to produce the questions in such a way that they were suitable in the given context. No feedback was provided during the actual experiment. Productions were recorded using a head-mounted unidirectional dynamic Shure SM10A microphone with an audio interface audient iD14. They were digitised directly onto a PC $(44.1 \mathrm{kHz}, 16 \mathrm{Bit}$, stereo). Acoustic measurements were performed with Praat (Boersma \& Weenink 2018).

\subsubsection{Participants}

The experiment was carried out at the University of Alberta, Canada. Twenty-one native speakers of English participated for a small fee ( 7 male, 14 female, average age $=22.5$ years). The participants were unaware of the purpose of the experiment. Among the participants were 18 speakers of Western Canadian, one speaker of Eastern Canadian, one of Ontario English, and one of Standard American. The participants were tested in a sound-attenuated room at the university. They were assigned to one of the lists.

\subsubsection{Data treatment}

The data were first coded on the word level; hesitations and pauses were marked separately $(\mathrm{P})$. Productions containing slips of the tongue and errors were removed from the analysis (33 wh-questions, 18 ISQs, 17 RQs, and 23 polar questions, 13 ISQs, 10 RQs). This left 429 wh-questions (213 ISQs and 216 RQs, 92.9 per cent of the total data) and 433 polar questions (218 ISQs and 215 RQs, 93.4 per cent of the total data) for analysis.

For the phonological analysis, pitch accents and edge tones were annotated by the first author following MAE_ToBI (Silverman et al. 1992; Beckman \& Ayers 1997; Beckman et al. 2005). A random selection of 15 per cent of the recordings was also annotated by the 
second author. Agreement was 84 per cent, Cohen's kappa 0.82, which is interpreted as almost perfect agreement (Landis \& Koch 1977). All questions that entered the analysis were produced in one Intonational Phrase, which was expected given their length and syntactic structure. $^{6}$

For the phonetic analyses, initial pitch was operationalised as in Sicoli et al. (2015). First, the f0-value at the point of maximum intensity in the first accented syllable was extracted (this was typically the wh-word in wh-questions, and the subject anyone in polar questions; see below). Next, we extracted the speaker's median pitch for each utterance, and the 90 per cent quantile and classified the data as high initial pitch if the extracted initial f0-value lay in the top 10 per cent of the speaker's pitch range. Furthermore, as suggested by an anonymous reviewer, we also extracted the average $\mathrm{f} 0$ of the first word (the auxiliary in polar questions and the wh-word in $w h$-questions). The duration of the subject (anyone) in polar questions and the $w h$-word in $w h$-questions, as well as the syntactic object, was automatically extracted from the annotation. As an acoustic measure for voice quality, we extracted $\mathrm{H} 1 *-\mathrm{A} 3 *$ at the midpoints of stressed vowels (the difference in $\mathrm{dB}$ between the amplitude of the first harmonic, f0, and the third formant, corrected for the frequency of the formants, cf. Mooshammer 2010). Higher values of H1*-A3* mean a steeper slope and thus less energy in the region of the third formant, which is characteristic for breathy voice (see DiCanio 2009 for different spectral tilt measures and their relation to glottal activity). A student assistant trained in phonetic annotation labeled the mid of the modally voiced part of the vowel in the stressed syllable of the object as well as the subject (in polar questions) and the $w h$-word (in wh-questions), using the waveform and a broadband spectrogram. In cases where the modally voiced part was shorter than $40 \mathrm{~ms}$ the item was excluded from this part of the analysis.

For the statistical analyses of accent types and edge tones, we coded one of the observed accent types (or edge tones) as 1 and the others as 0 and calculated logistic multilevel regression models with participants and items as crossed random factors (using the R-function glmer()) and illocution type as fixed factor. The initial models included random intercepts for participants and items only; these were compared to models with a more complex random-effects structure (with random slopes for illocution for participants and items). The model with the best fit to the data (as operationalised by LogLikelihood comparisons in the R-function anova()) is reported. The same procedure was performed for the binary variable high initial pitch (in the top 10 per cent of the speaker's range or not). For the statistical analysis of the continuous

\footnotetext{
${ }^{6}$ A reviewer asks whether the annotators were aware at the time of the phonological annotation of whether each question had been produced as RQ or ISQ and remarks that it would be preferable for the annotation to be done blindly. The annotators were in fact aware of whether a question had been produced in an RQ or ISQ context, since this was automatically coded in the file names. However, had the annotators been unaware of the produced illocution type of each question, it would still have been obvious immediately when listening to the files, given the clear phonetic differences, in duration in particular, between the illocution types (see section 2.2). It would therefore have been impossible to annotate the sound files without this knowledge, with very few exceptions.
} 
phonetic variables, we calculated linear-mixed effects regression models with participants and items as crossed random factors (using the R-function lmer() and the package lmerTest) and illocution type as fixed factor. The model fitting procedure was the same as for the categorical analyses. In case the distribution of prosodic parameters across illocution type was different for the three speakers of varieties other than Western Canadian (it turned out that this was the case only for accent types in wh-questions), we also analysed the subset of the eighteen Western Canadian speakers with the same model fitting as described above (it turned out that the findings remained the same as in the entire data set). To account for the fact that multiple variables were tested we adjusted the p-values using the Benjamini-Hochberg correction (Benjamini \& Hochberg 1995) within question types. We only report the adjusted values.

\subsection{Results}

We start with a presentation of the results for wh-questions and then turn to polar questions. In each subsection we first report the results for edge tones, nuclear and prenuclear pitch accent types, followed by the prototypical tunes produced in RQ and ISQ contexts. Then we present systematic phonetic differences.

\subsubsection{Wh-questions}

All numbers relate to a total of $429 w h$-questions which entered the analysis (213 ISQs, $216 \mathrm{RQs})$.

\section{Edge tone}

The most frequent edge tone for both ISQs ( $\mathrm{N}=189 ; 89$ per cent) and RQs $(\mathrm{N}=187 ; 87$ per cent) was $\mathrm{L}-\mathrm{L} \%$. There is no effect of illocution type on edge tone in $w$-questions $(\mathrm{p}=0.7)$.

\section{Accent on the object noun}

As illustrated in figure 1, which includes all observed accent types, the distribution of accents on the object was different for RQs and ISQs. Specifically, results showed significantly more nuclear $\mathrm{L}+! \mathrm{H}^{*}$ accents in RQs than in ISQs $(\beta=2.3, \mathrm{SE}=0.5, \mathrm{z}=$ $4.6, \mathrm{p}=0.002$ ). In ISQs, on the other hand, the nuclear accent on the noun is more often realised with monotonal $! \mathrm{H}^{*}$ than in RQs, a difference that approached significance $(\beta=0.7, \mathrm{SE}=0.4, \mathrm{z}=1.9, \mathrm{p}=0.07)$, and significantly more often with monotonal $\mathrm{H}^{*}(\beta=3.7, \mathrm{SE}=1.1, \mathrm{z}=3.5, \mathrm{p}=0.002)^{7}$

\footnotetext{
${ }^{7}$ For the three speakers of varieties other than Western Canadian, $\mathrm{H}^{*}, ! \mathrm{H}^{*}$ and $\mathrm{L}+\mathrm{H}^{*}$ were equally frequent in ISQs (10, 8 and 10 times, respectively). If we exclude these three speakers, the results of the statistical analyses do not change: more nuclear $\mathrm{L}+\mathrm{H}^{*}$ in RQs than in ISQs $(\beta=1.6, \mathrm{SE}=0.3, \mathrm{z}=6.1, \mathrm{p}=0.007)$, more $! \mathrm{H}^{*}$ in ISQs than RQs $(\beta=0.9, \mathrm{SE}=0.26, \mathrm{z}=3.6, \mathrm{p}=0.002)$, and more $\mathrm{H}^{*}$ in ISQs than in RQs $(\beta=3.1, \mathrm{SE}=1.1, \mathrm{z}=2.7, \mathrm{p}<0.01)$.
} 


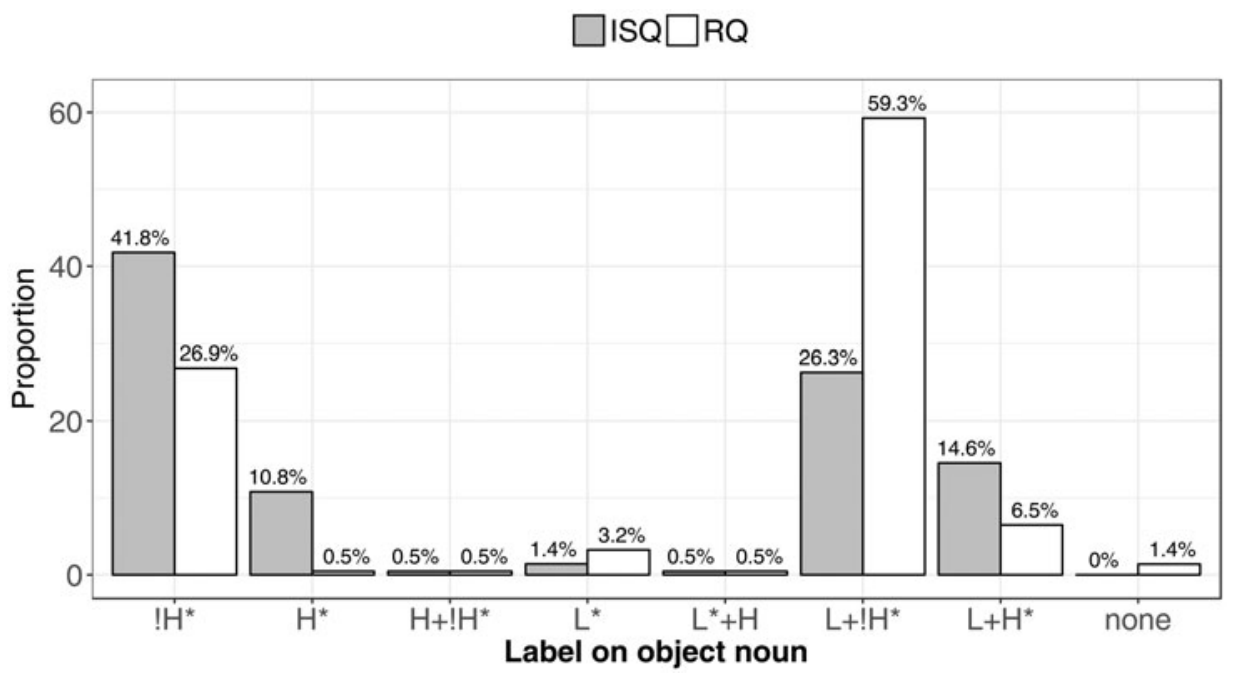

Figure 1. Proportion of accent types on the object across illocution types in wh-questions

\section{Accents on the wh-word and verb}

There is no difference in frequency of prenuclear accent placement on the $w h$-word between ISQs and RQs $(p>0.9)$, however, there is a difference in accent type. If accented, the $w h$-word who was more often accented with an $\mathrm{L}^{*}+\mathrm{H}$ accent in RQs than in ISQs $(\beta=1.3, \mathrm{SE}=0.2, \mathrm{z}=5.4, \mathrm{p}=0.0005)$. Conversely, there were significantly more $H^{*}$ accents in ISQs compared to RQs $(\beta=1.4, \mathrm{SE}=0.27, \mathrm{z}=5.1, \mathrm{p}=0.0005)$; see figure 2.

The verb was unaccented in more than 80 per cent in both illocution types (ISQ: $\mathrm{N}=181,85$ per cent, RQ: $\mathrm{N}=178,82$ per cent); there was no effect of illocution type $(\mathrm{p}=0.9)$. For both the $w h$-word and the verb, there were no differences in the distribution of accent types between Western Canadian speakers and non-Western Canadian speakers.

\section{Overall tunes}

Combining prenuclear and nuclear accents with edge tone, we observe a number of tunes occurring frequently in ISQs and RQs. Those that occurred more than 10 times in either or both of the illocution types are given in table 3 . The verb as accent position is omitted here due to the lack of significant differences between illocution types.

Three tunes were particularly frequent with ISQs, adding up to 100 occurrences (47 per cent):

- $\mathrm{H}^{*}$ ! H* L-L\%; with 34 occurrences (16 per cent) in ISQs vs only 8 occurrences (3.7 per cent) in RQs this tune can be seen as a specific tune for ISQs; see figure 3 for an example 


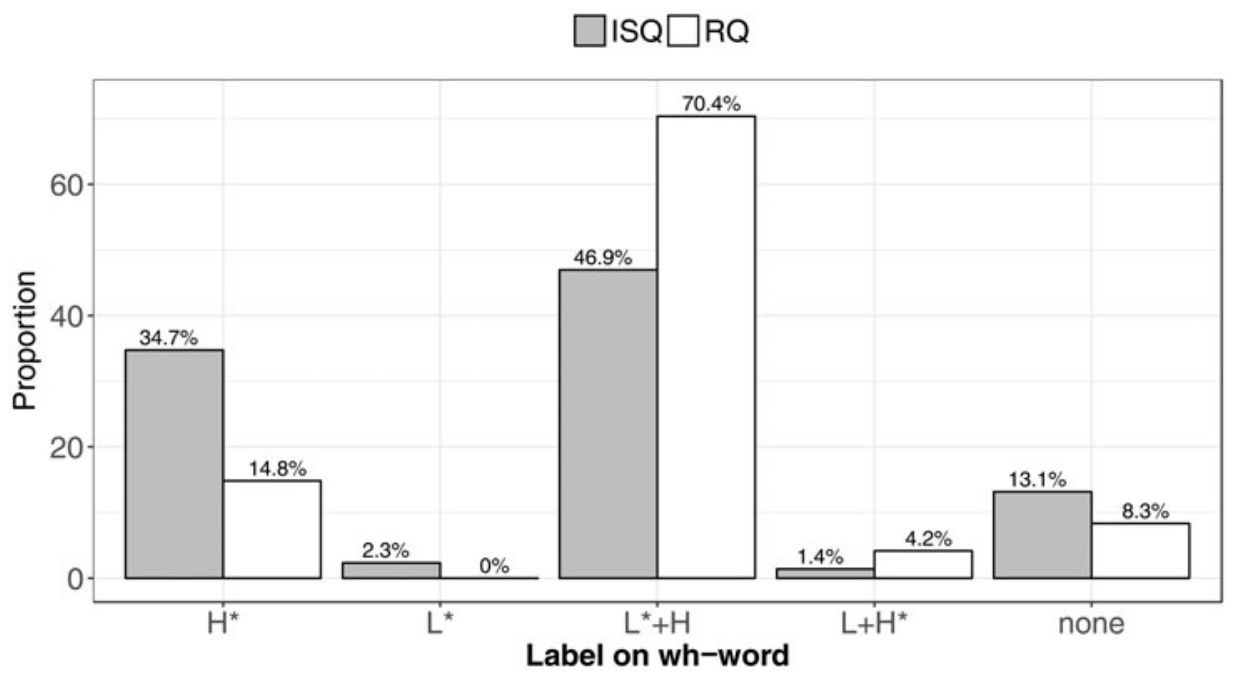

Figure 2. Proportion of pitch accents on the wh-word across illocution types

Table 3. Overview of the tunes that occurred at least 10 times in either or both of the illocution types, sorted by the label on the object

\begin{tabular}{llllrc}
\hline \hline $\begin{array}{l}\text { Label on } w h \text {-word } \\
\text { (prenuclear accent) }\end{array}$ & $\begin{array}{l}\text { Label on the object } \\
\text { noun (nuclear accent) }\end{array}$ & $\begin{array}{l}\text { Edge } \\
\text { tone }\end{array}$ & $\begin{array}{l}\text { ISQ } \\
(\mathrm{N}=213)\end{array}$ & $\begin{array}{l}\text { RQ } \\
(\mathrm{N}=216)\end{array}$ & $\begin{array}{l}\text { Ratio } \\
\text { ISQ:RQ }\end{array}$ \\
\hline $\mathrm{H}^{*}$ & $\mathrm{~L}+\mathrm{H}^{*}$ & $\mathrm{~L}-\mathrm{L} \%$ & 12 & 3 & 4.0 \\
$\mathrm{H}^{*}$ & $\mathrm{~L}+\mathrm{H}^{*}$ & $\mathrm{~L}-\mathrm{L} \%$ & 12 & 11 & 1.1 \\
$\mathrm{~L}^{*}+\mathrm{H}$ & $\mathrm{L}+\mathrm{H}^{*}$ & $\mathrm{~L}-\mathrm{L} \%$ & 29 & 91 & 0.3 \\
$\mathrm{H}^{*}$ & $! \mathrm{H}^{*}$ & $\mathrm{~L}-\mathrm{L} \%$ & 34 & 8 & 4.3 \\
$\mathrm{~L}^{*}+\mathrm{H}$ & $! \mathrm{H}^{*}$ & $\mathrm{~L}-\mathrm{L} \%$ & 37 & 35 & 1.1 \\
\hline Sum & & & 124 & 148 & \\
\hline \hline
\end{tabular}

- $\mathrm{L}^{*+\mathrm{H}}$ ! H* L-L\%; with 37 (ISQ, 17.4 per cent) vs 35 (RQ, 16.2 per cent) occurrences this tune is the most frequent one for ISQs, but it is unspecific with regard to illocution type, because it occurs in RQs with similar frequency

- $\mathrm{L}^{*}+\mathrm{H} \mathrm{L}+$ ! H* L-L\%; with 29 (ISQ, 13.6 per cent) vs 91 (RQ, 42.1 per cent) occurrences this tune is frequent for ISQs, but it is much more frequent - and thus very specific - for RQs; see below.

There are a number of other overall tunes, which are very specific for ISQs (in that they are only or mostly used in ISQ contexts), but which are overall very rare. These include $\mathrm{H}^{*} \mathrm{~L}+\mathrm{H}^{*} \mathrm{~L}-\mathrm{L} \%\left(\mathrm{~N}=12\right.$ in ISQ, $\mathrm{N}=3$ in RQ contexts), $\mathrm{L}^{*}+\mathrm{H} \mathrm{H}^{*} \mathrm{~L}-\mathrm{L} \%(\mathrm{~N}=$ 8 in ISQ, $\mathrm{N}=0$ in RQ contexts) and no accent on the $w h$-word, $\mathrm{H}^{*} \mathrm{~L}-\mathrm{L} \%(\mathrm{~N}=6$ in ISQ, $\mathrm{N}=1$ in RQ contexts).

The most frequent and at the same time very specific contour for RQs had an $\mathrm{L}^{*}+\mathrm{H}$ accent on the $w h$-word and an $\mathrm{L}+! \mathrm{H}^{*}$ on the object noun, followed by a low edge tone 

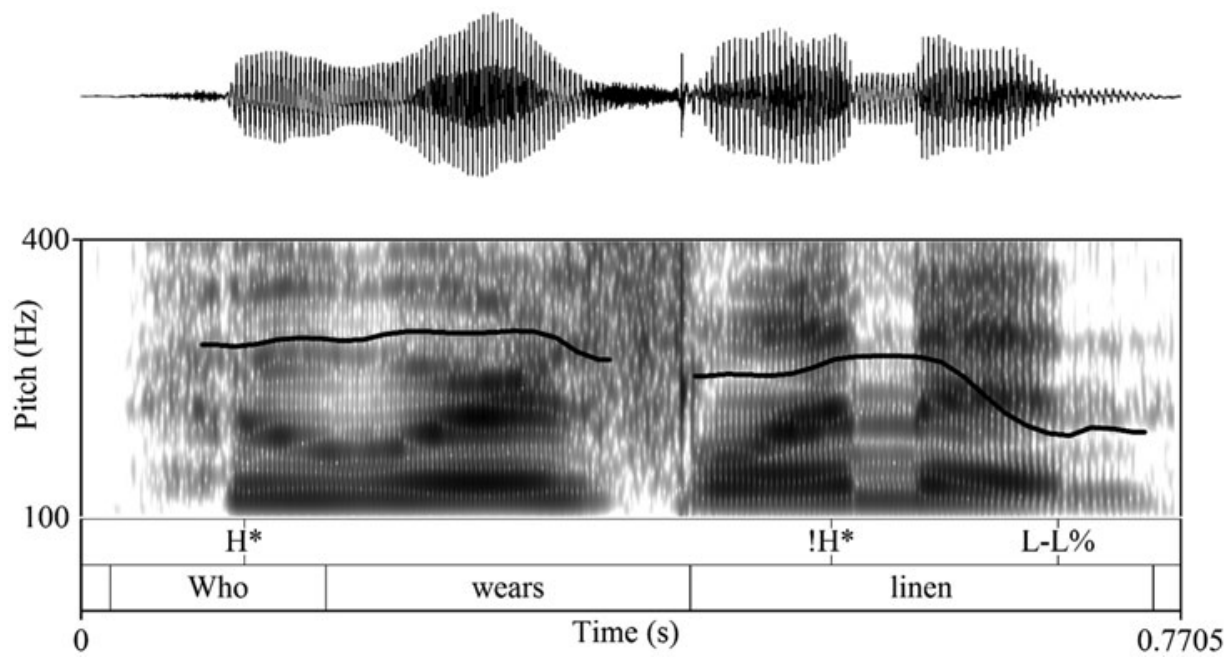

Figure 3. Example of a frequent prosodic realisation of a wh-ISQ (vp16, female)
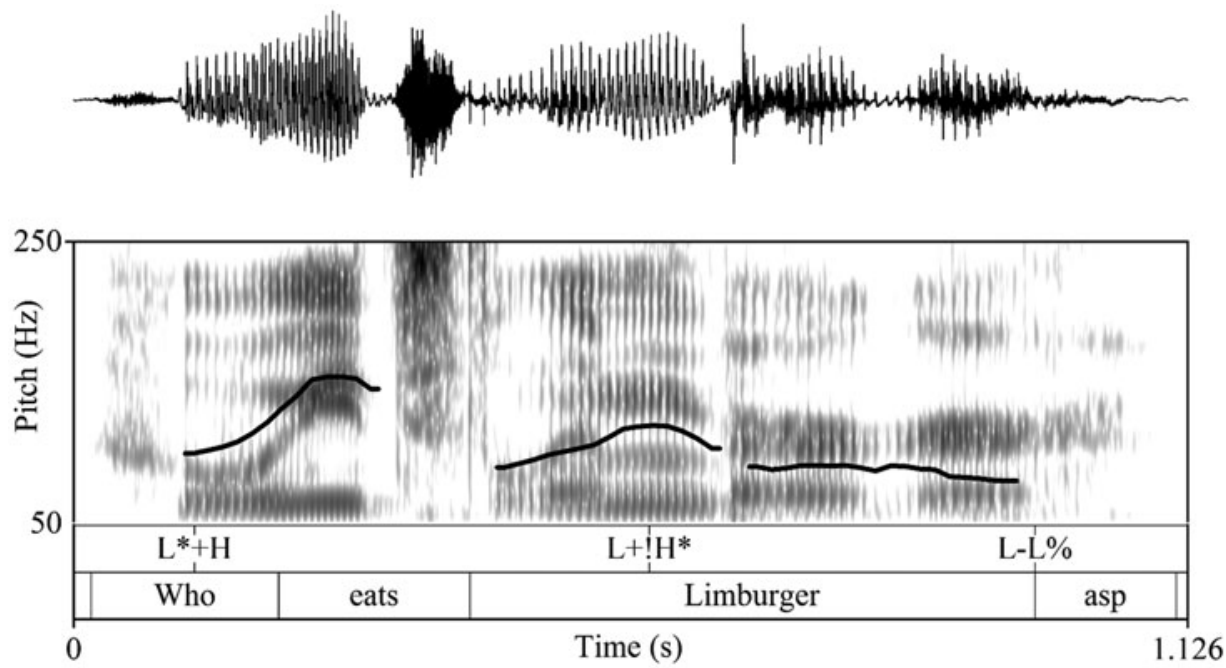

Figure 4. Example of a frequent prosodic realisation of a $w h$-RQ (vp02, male)

L-L\% ( $\mathrm{N}=91,42$ per cent in RQs vs $\mathrm{N}=29,14$ per cent ISQs); see figure 4. Note that this contour accounted for 42 per cent of the RQ realisations.

Phonetic analyses: initial pitch, duration and voice quality

For the categorical variable high initial pitch, twelve utterances had to be discarded because no f0-value could be extracted in the wh-word $(<3$ per cent of the 


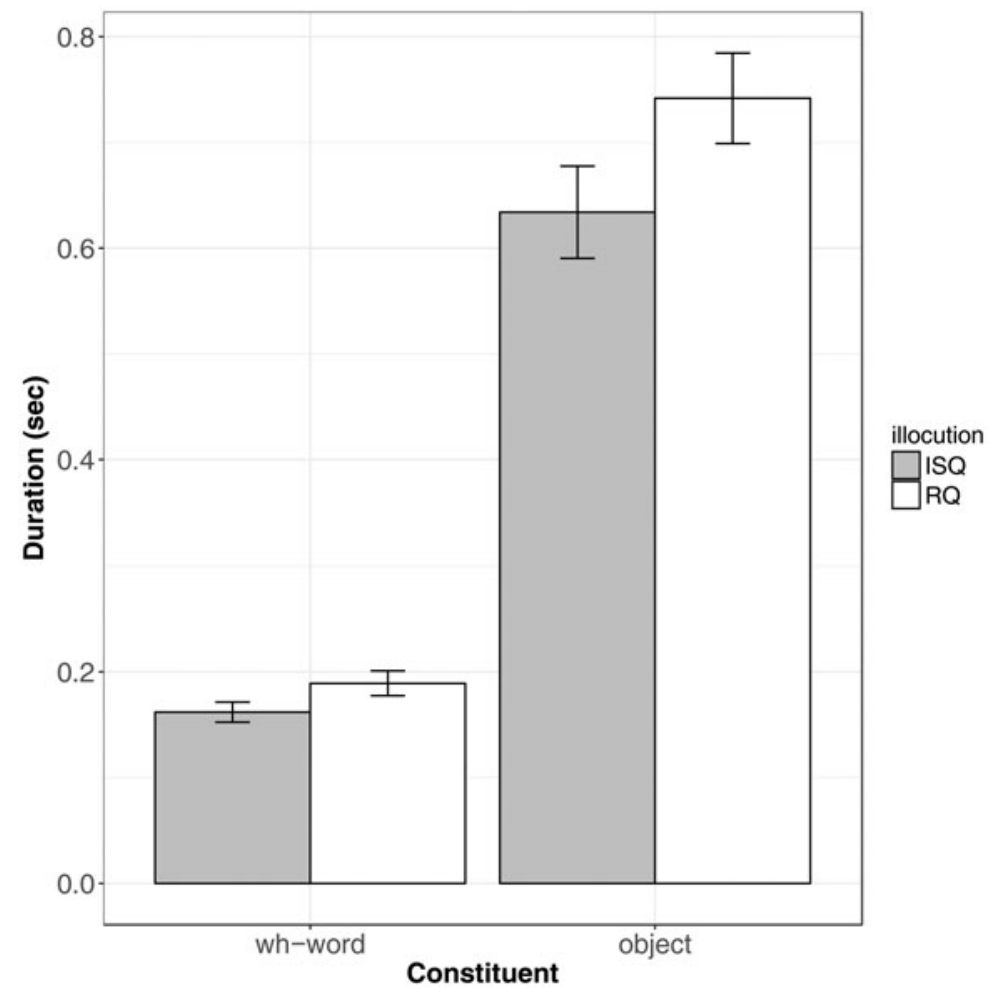

Figure 5. Average duration of the object and the $w h$-word across illocution types (whiskers indicate standard errors)

$w h$-questions). Results showed that in 31 utterances, initial pitch lay in the top 10 per cent of the speaker's pitch range (20 for ISQs, 11 for RQs). A generalised linear mixed effects regression model showed that this difference was not significant $(p>0.9)$. The average $f 0$ in the $w h$-word was higher in ISQs than in RQs (245.9 Hz in ISQs vs $232.7 \mathrm{~Hz}$ in RQs), but this difference was not significant, either $(\mathrm{p}>0.1)$.

The duration measures showed longer absolute durations of the $w h$-word and the object in RQs compared to ISQs; see figure 5. The $w h$-word was on average $28 \mathrm{~ms}$ longer in RQs than in ISQs $(\beta=28.4, \mathrm{SE}=6.8, \mathrm{t}=20.9, \mathrm{p}=0.007)$. The duration of the syntactic object was $104 \mathrm{~ms}$ longer in RQs than in ISQs $(\beta=104.2, \mathrm{SE}=12.7$, $\mathrm{t}=8.2, \mathrm{p}=0.002)$. Note that adding the accent type realised on the syntactic object or the edge tone did not improve the fit of the model $\left(x^{2}(11)=17.1, p>0.1, x^{2}(5)=1.7\right.$, $\mathrm{p}>0.8$, respectively).

$\mathrm{H} 1 *-\mathrm{A} 3 *$ were extracted at the middle of the $w h$-word who and the middle of the stressed vowel of the object noun. Items in which the object noun was not stressed consistently by all participants (pasta bolognese, mayonnaise, brussels sprouts, codliver oil) and one instance in which the stress was on the wrong syllable (lambada) were not included in the analysis (excluding 93 items). Furthermore, 15 ISQs (4 in 
wh-word and 11 in object noun) and 23 RQs ( 3 in $w h$-word and 20 in object noun) were excluded due to strong glottalisation, which made f0-extraction (and hence $\mathrm{H} 1$ extraction) impossible. This left 425 items for the $\mathrm{H} 1 *-\mathrm{A} 3 *$ analysis of the $w h$-word and 307 items for the $\mathrm{H} 1{ }^{*}$-A 3 analysis of the object noun. Results of linear-mixed effects regression models showed that the $w h$-word was produced with higher $\mathrm{H} 1 *-\mathrm{A} 3 *$ values in RQs than in ISQs (31.4 vs 27.2, $\beta=4.3, \mathrm{SE}=0.6, \mathrm{df}=20.5, \mathrm{t}=6.7, \mathrm{p}=0.002$ ), indicating a softer, breathier voice quality for RQs. There was no effect of illocution type on the $\mathrm{H} 1 *$-A $3 *$ values extracted from the noun $(\mathrm{p}>0.9)$.

\subsubsection{Polar questions}

All numbers relate to a total of 433 polar questions that entered the analysis (218 ISQs, 215 RQs).

\section{Edge tones}

Unlike in $w h$-questions, there was an effect of illocution type on edge tone; see figure 6. Although $\mathrm{H}-\mathrm{H} \%$ was overall very frequent in both ISQs and RQs, there were significantly more $\mathrm{H}-\mathrm{H} \%$ in ISQs ( $\mathrm{N}=179,82$ per cent) than in RQs $(\mathrm{N}=98,46$ per cent); $\beta=2.7$, $\mathrm{SE}=0.8 . \mathrm{z}=3.4, \mathrm{p}<0.0006$. At the same time, $\mathrm{RQs}$ were comparatively more often realised with $\mathrm{H}-\mathrm{L} \%(\mathrm{~N}=115,53$ per cent) than ISQs $(\mathrm{N}=20,9$ per cent), $\beta=5.0$, $\mathrm{SE}=2.0, \mathrm{z}=2.4, \mathrm{p}<0.02$. This means that RQs did not have as many steep rises as ISQs; instead, they had comparatively more rises ending in mid-level plateaus. To corroborate the manual labelling of the two types of final rises (steep rise $\mathrm{H}-\mathrm{H} \%$ vs plateau H-L\%) and thus validate the difference, we compared the mean f0-excursion for $\mathrm{H}-\mathrm{H} \%$ vs $\mathrm{H}-\mathrm{L} \%$ edge tones in the sentence-final object. The results showed a larger $\mathrm{f} 0$-excursion for boundaries labelled as $\mathrm{H}-\mathrm{H} \%$ (10.2 st) compared to boundaries labelled as $\mathrm{H}-\mathrm{L} \%(5.0 \mathrm{st})$, a difference that was statistically significant $(\beta=5.2$, $\mathrm{SE}=0.7, \mathrm{df}=250, \mathrm{t}=7.2, \mathrm{p}<0.0001)$. There was no effect of illocution type and no interaction between illocution type and boundary tone (both $\mathrm{p}>0.15$ ). The distributions of edge tones across illocution types was nearly identical for the Western Canadian and the non-Western Canadian participants.

\section{Accent on the object noun}

Although the nuclear accent was most often realised on the object noun in both ISQs and RQs (ISQs: $N=204,93.6$ per cent; RQs: $N=153,71.2$ per cent), there were more cases of unaccented objects in $\mathrm{RQs}(\mathrm{N}=62,28.8$ per cent) than in ISQs $(\mathrm{N}=14,6.4$ per cent); see 'none' in figure 7. This difference was significant $(\beta=-8.0, \mathrm{SE}=2.8, \mathrm{z}=2.8, \mathrm{p}=0.04)$. When the object was unaccented, the nuclear accent was realised on the subject (anyone). The most frequent accent type on the object was $\mathrm{L}^{*}$, but there were significantly more $\mathrm{L}^{*}$ accents in ISQs than in RQs (186 vs 143, $\beta=2.8, \mathrm{SE}=1.0, \mathrm{z}=2.8, \mathrm{p}=0.02)$. Western Canadian and non-Western Canadian speakers behaved the same. 


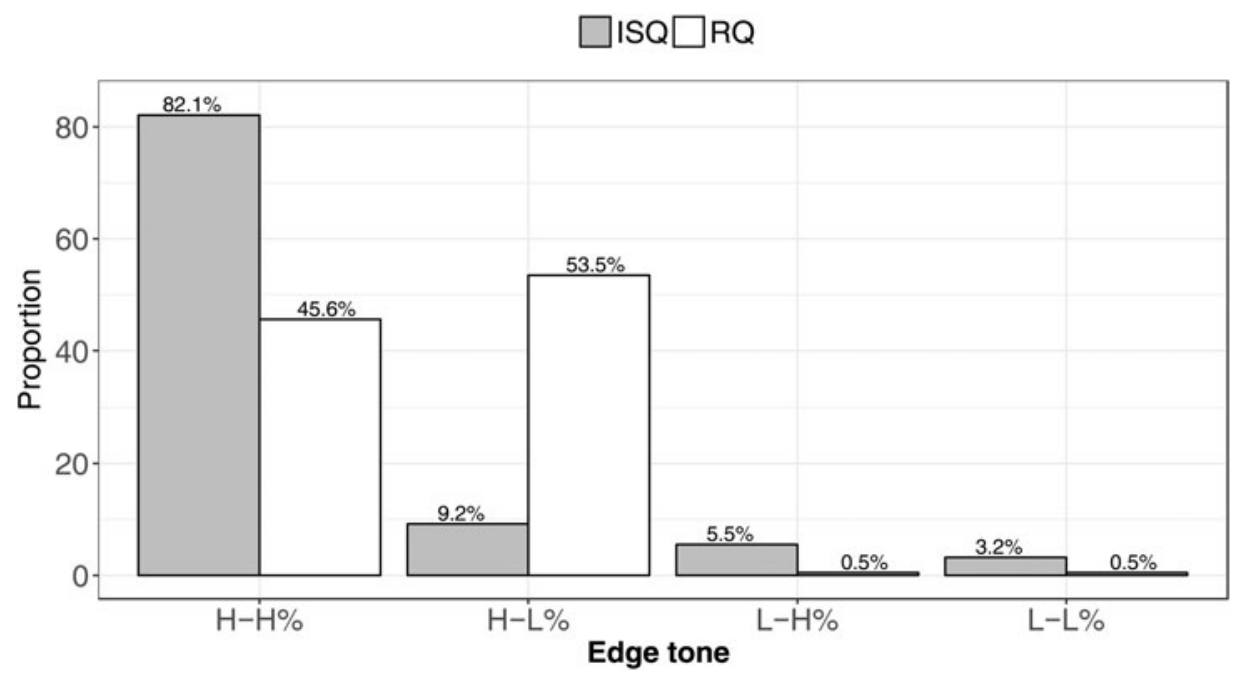

Figure 6. Proportion of edge tones across illocution types in polar questions

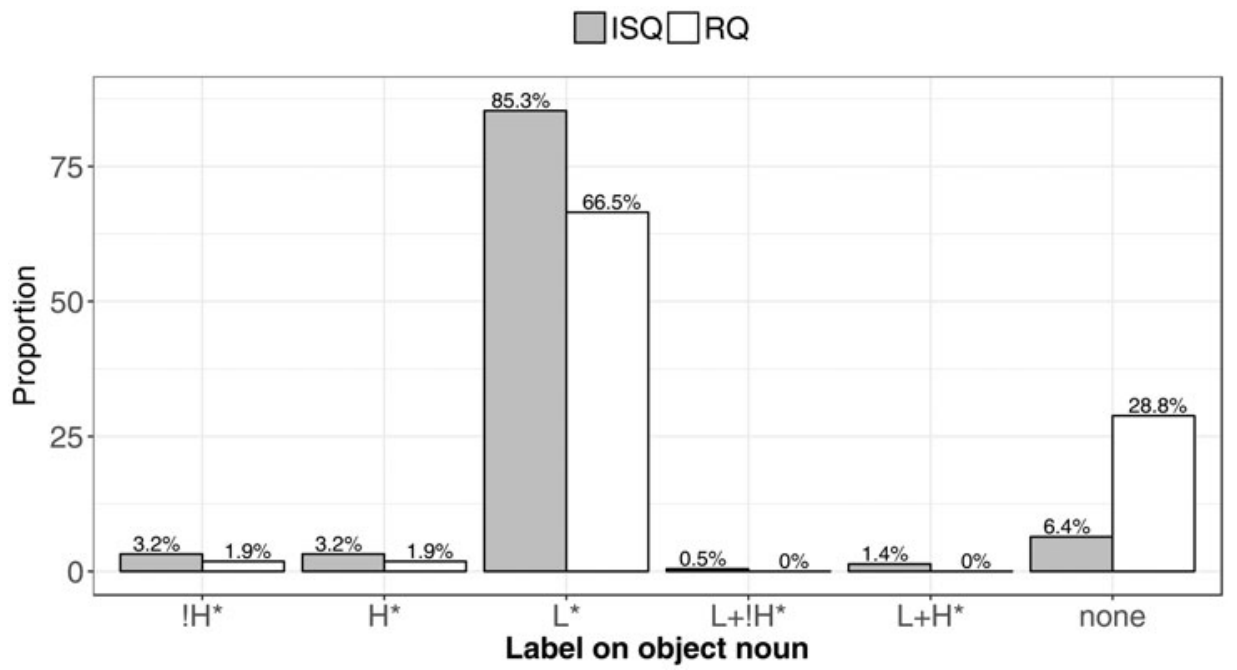

Figure 7. Proportion of accents on the object noun across illocution types in polar questions

Accents on the auxiliary, the verb and the subject

The sentence-initial auxiliary (does) was typically unaccented $(\mathrm{N}=215,98.2$ per cent in ISQs; $\mathrm{N}=214,99.3$ per cent in RQs), with no difference between illocution types $(p>0.9)$. The lexical verb was mostly unaccented, but there were more unaccented 


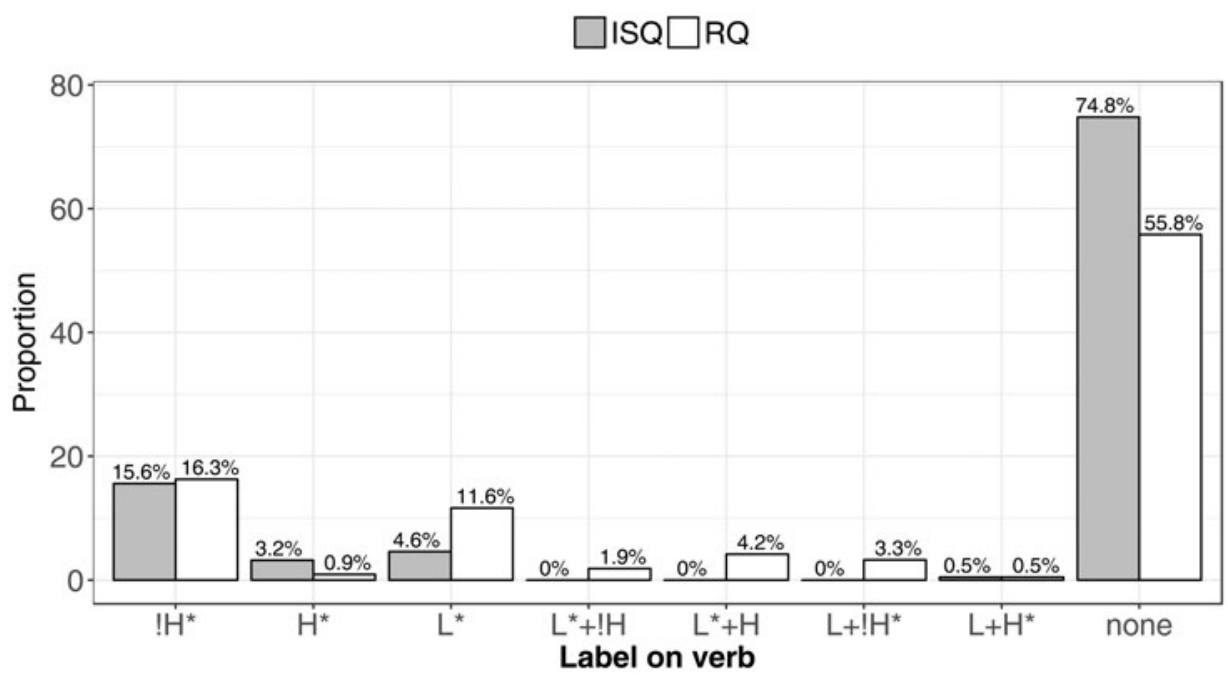

Figure 8. Proportion of accents on the verb across illocution types in polar questions

$\square \mathrm{ISQ} \square \mathrm{RQ}$

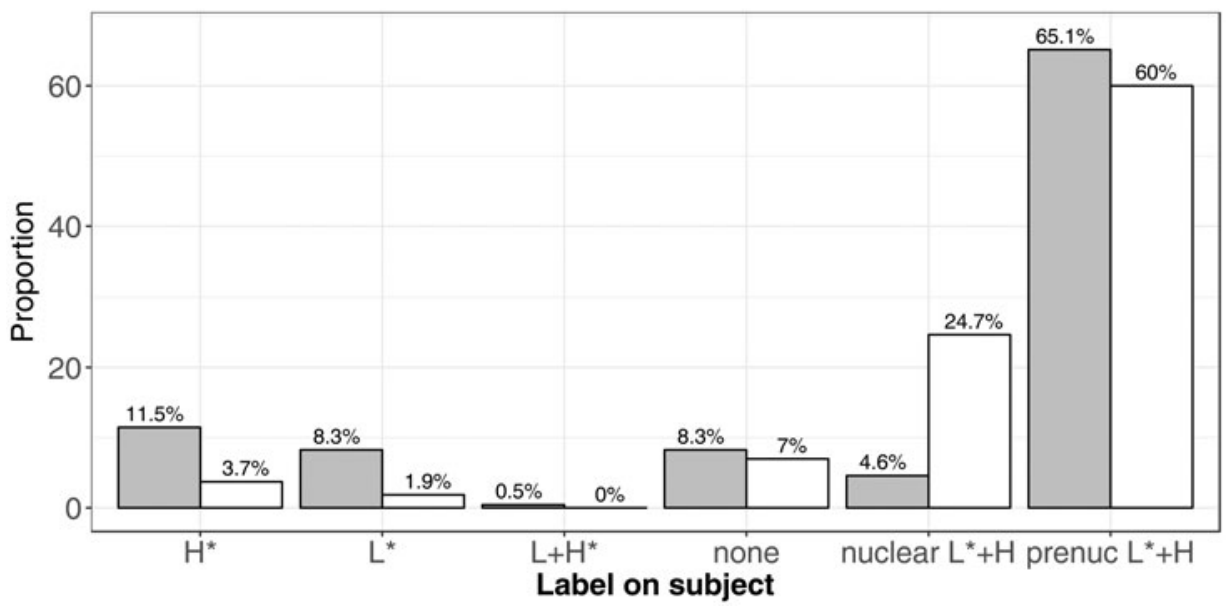

Figure 9. Proportion of accents on the subject anyone across illocution types in polar questions

verbs in ISQs than in RQs $(\mathrm{N}=163,74.8$ per cent in ISQs; $\mathrm{N}=120,55.8$ per cent in RQs, $\beta=9.0, \mathrm{SE}=3.4, \mathrm{z}=2.6, \mathrm{p}=0.02$ ); see figure 8 .

There were significantly more nuclear $\mathrm{L}^{*}+\mathrm{H}$ accents on the subject anyone in RQs than in ISQs $(\mathrm{N}=54$ vs $10,28.7$ vs 4.6 per cent; $\beta=5.6, \mathrm{SE}=2.6, \mathrm{z}=2.2, \mathrm{p}=0.04)$; see figure 9. For accents on the auxiliary, the verb and the subject, there were no differences between Western Canadian and non-Western Canadian speakers. 
Table 4. Overview of the tunes that occurred at least 10 times ( $>5$ per cent) in either or both of the illocution types in polar questions, sorted by the label on the object. Note that the first five tunes have the nuclear accent on the object, and the last two contours on the subject anyone

\begin{tabular}{lllrrc}
\hline \hline $\begin{array}{l}\text { Accent label } \\
\text { on subject }\end{array}$ & $\begin{array}{l}\text { Accent label } \\
\text { on object }\end{array}$ & $\begin{array}{l}\text { Edge } \\
\text { tone }\end{array}$ & $\begin{array}{l}\text { ISQ } \\
(\mathrm{N}=218)\end{array}$ & $\begin{array}{l}\text { RQ } \\
(\mathrm{N}=215)\end{array}$ & $\begin{array}{l}\text { Ratio ISQ: } \\
\text { RQ }\end{array}$ \\
\hline $\mathrm{H}^{*}$ & $\mathrm{~L}^{*}$ & $\mathrm{H}-\mathrm{H} \%$ & 21 & 4 & 5.3 \\
$\mathrm{~L}^{*}$ & $\mathrm{~L}^{*}$ & $\mathrm{H}-\mathrm{H} \%$ & 18 & 1 & 18 \\
$\mathrm{~L}^{*}+\mathrm{H}$ & $\mathrm{L}^{*}$ & $\mathrm{H}-\mathrm{H} \%$ & 114 & 60 & 1.9 \\
0 & $\mathrm{~L}^{*}$ & $\mathrm{H}-\mathrm{H} \%$ & 15 & 7 & 2.1 \\
$\mathrm{~L}^{*}+\mathrm{H}$ & $\mathrm{L}^{*}$ & $\mathrm{H}-\mathrm{L} \%$ & 13 & 59 & 0.2 \\
$\mathrm{~L}^{*}+\mathrm{H}$ & 0 & $\mathrm{H}-\mathrm{H} \%$ & 7 & 18 & 0.4 \\
$\mathrm{~L}^{*}+\mathrm{H}$ & 0 & $\mathrm{H}-\mathrm{L} \%$ & 2 & 34 & 0.06 \\
\hline Sum & & & 190 & 183 & \\
\hline \hline
\end{tabular}

\section{Overall tunes}

By far the most frequent contour for ISQs $(\mathrm{N}=114,52$ per cent; see table 4) had a prenuclear $\mathrm{L}^{*}+\mathrm{H}$ accent on the subject, followed by a low $\left(\mathrm{L}^{*}\right)$ nuclear accent on the object and a rise to a high boundary ( $\mathrm{H}-\mathrm{H} \%)$. This contour, illustrated in the upper panel of figure 10, occurred nearly twice as often in ISQs than in RQs (N=114 vs 60; 52 vs 28 per cent). The remaining three contours that were more frequent in ISQs than in RQs also had an L* nuclear accent on the object, followed by an $\mathrm{H}-\mathrm{H} \%$ edge tone (see bottom panel of figure 10 for an example). Taken together, the four rising nuclear contours ( $\left.\mathrm{L}^{*} \mathrm{H}-\mathrm{H} \%\right)$ made up 77 per cent of ISQ contours $(\mathrm{N}=168)$.

The most frequent contour for RQs $(\mathrm{N}=60,28$ per cent) was the one that occurred even more frequently in ISQs $\left(\mathrm{L}^{*}+\mathrm{H}\right.$ on the subject, nuclear $\mathrm{L}^{*}$ on the object, followed by an $\mathrm{H}-\mathrm{H} \%$ edge tone). The next frequent contour in RQs $(\mathrm{N}=$ 59,27 per cent) was similar to the former contour except that the final boundary was $\mathrm{H}-\mathrm{L} \%$, and hence did not rise as high but ended in a plateau (see top panel of figure 11). Finally, contours in which the nuclear accent was realised on the subject were rather frequent in $\mathrm{RQs}(\mathrm{N}=52$ in total, 24 per cent) and did not occur often in ISQs $(\mathrm{N}=9,4$ per cent); see bottom panel of figure 11 for illustration. Note that a nuclear accent on the subject was also frequently followed by a plateau edge tone $\mathrm{H}-\mathrm{L} \%(\mathrm{~N}=34,16$ per cent $)$.

\section{Phonetic analyses}

Initial pitch was extracted from the subject anyone as described before. Six utterances were excluded because no f0-value could be extracted $(<2$ per cent of the polar 

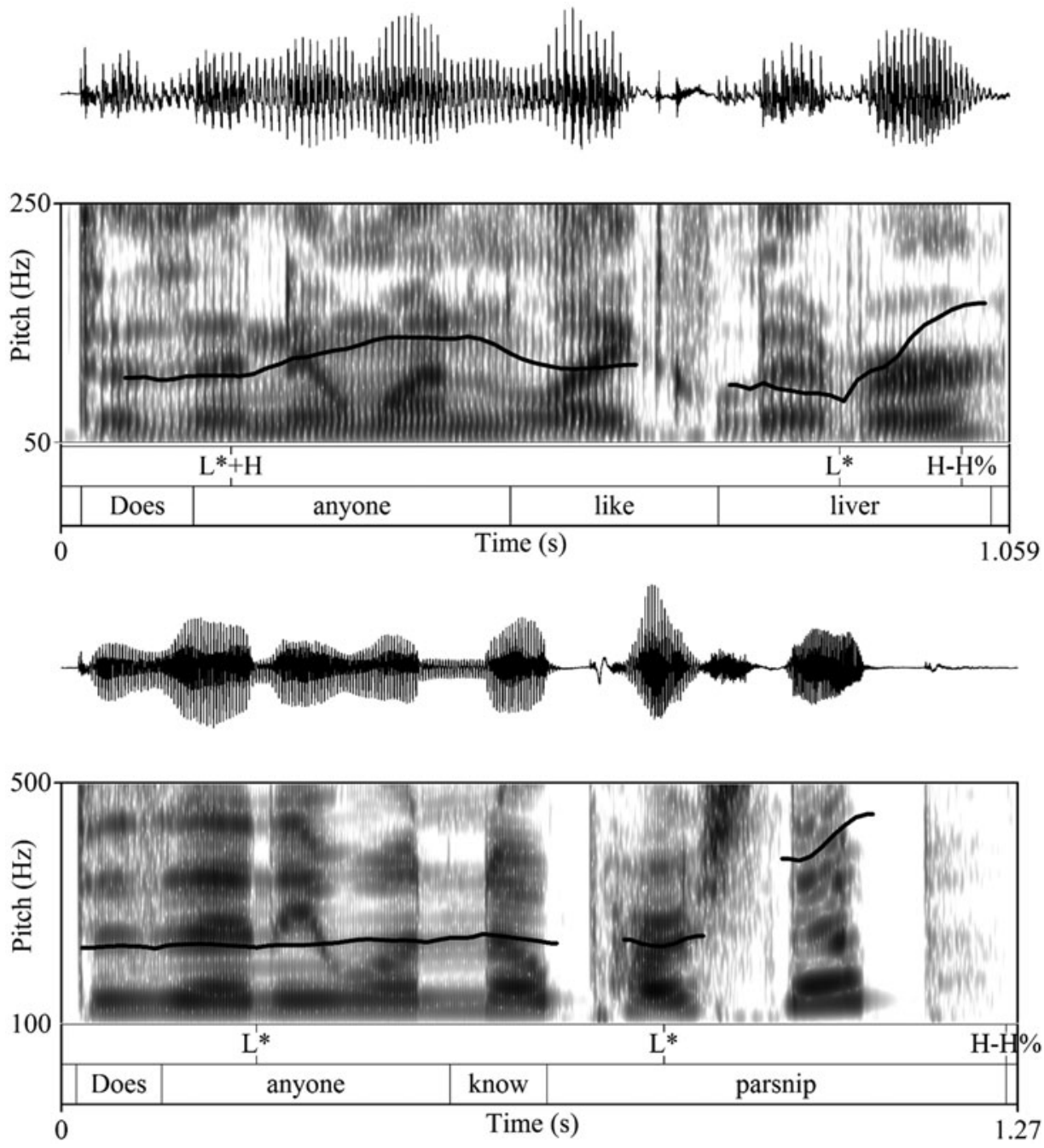

Figure 10. Frequent realisations of a polar question in an information-seeking context (top panel: vp12, male; bottom panel: vp07, female)

questions). Forty-four utterances started with an f0 value in the top 10 per cent of the speaker's pitch range. These were 35 RQs and 9 ISQs, a difference between illocution types that was significant $(\beta=1.5, \mathrm{SE}=0.4, \mathrm{z}=3.9, \mathrm{p}<0.0007)$. This effect does not occur when comparing mean f0 in the auxiliary (ISQ: $195.3 \mathrm{~Hz}, \mathrm{RQ}: 189.2$ $\mathrm{Hz}, \mathrm{p}>0.3)$.

In terms of duration (see figure 12), the subject (anyone) was on average $50 \mathrm{~ms}$ longer in RQs than in ISQs $(\beta=50.0, \mathrm{SE}=8.1, \mathrm{t}=21.0, \mathrm{p}<0.02)$. Likewise, the object was 57 ms longer in RQs than in ISQs $(\beta=56.9, \mathrm{SE}=9.3, \mathrm{t}=20.6, \mathrm{p}<0.03)$. 



Figure 11. Frequent realisation of a polar question in a rhetorical context (top panel: vp08, female; bottom panel: vp29, female)

$\mathrm{H} 1$ *-A3* was extracted from the subject anyone and the object noun. In RQs, 45 items had to be discarded from the analysis of the subject due to creaky voice (26 cases in ISQs). For the remaining 357 cases, there was no difference in $\mathrm{H}^{*}$-A $3 *$ of the stressed syllable of the subject $(p=0.9)$. For the object, 37 items had to be excluded because of glottalisation (17 in ISQ and 20 in RQ contexts), four cases with whispered voice (1 in ISQ and 3 in RQ contexts), as well as 71 cases with variable stress (mayonnaise, Brussels sprouts, pasta bolognese, codliver oil). For the remaining 323 cases, there was no difference of illocution type $(\mathrm{p}=0.9)$. 


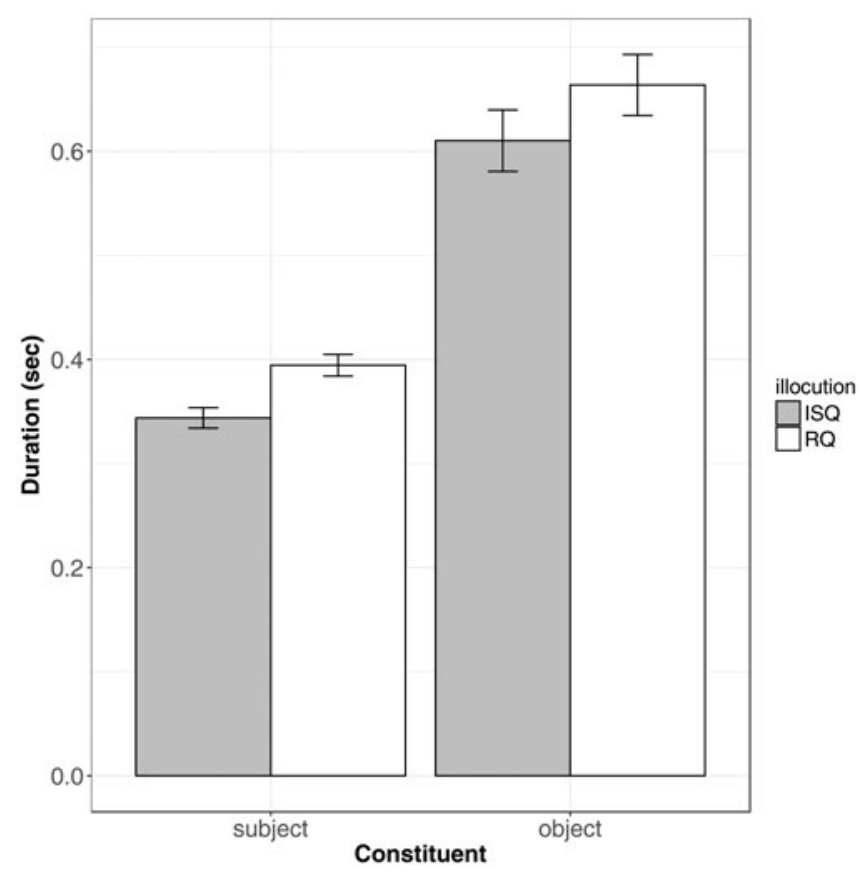

Figure 12. Average duration of the subject (anyone) and the object across illocution types in polar questions

\section{Discussion}

In what follows, we relate our findings to the hypotheses put forward in (3) above, repeated in (4) for convenience, as well as to the literature surveyed in the introductory sections.

(4) Hypotheses

H: ISQs and RQs differ in their prosodic realisation.

H1: In phonology, all tonal parameters, i.e. edge tones as well as nuclear and prenuclear pitch accents, contribute to the distinction between ISQs and RQs.

$\mathrm{H} 2$ : In phonetics, duration, voice quality and initial pitch contribute to the distinction between ISQs and RQs.

To begin with, our study confirms the general hypothesis H. Our results clearly show that despite some overlap in the use of intonational categories, ISQs and RQs differ substantially in their prosodic realisation. Crucially, while previous literature typically focuses on phonological differences, we show that cues to ISQ vs RQ interpretation are both phonological and phonetic in nature.

Our results confirm hypothesis $\mathrm{H} 1$, which maintains that all tonal parameters contribute to the distinction between RQs and ISQs. As outlined in the introduction, a lot of the semantic literature focuses on the terminus of the intonation contour, i.e. whether ISQs and RQs are realised with an utterance-final fall or a rise, and how the phrase accent and/or boundary tone is related to question meaning and speech acts. 
Our study shows that edge tones (and boundary tones) are distinctive only for polar questions, but not for $w h$-questions. Wh-questions are overwhelmingly falling to L-L\% across illocution types. This is compatible with Bartels (1999), who argues that for wh-questions, non-tonal rather than tonal cues - i.e. non-tonal cues rather than high vs low edge tones - are responsible for their interpretation. According to Bartels (1999: 257), L would 'highlight the assertive thrust of a [wh-] rhetorical interrogative' and 'serves as a cue to the ulterior statementhood of the utterance' (p. 259), i.e. the speaker will use it in order to avoid misunderstanding of an RQ as a genuine question on the part of the hearer.

Polar questions on the other hand are overwhelmingly rising, but while ISQs rise continuously to a high level in the speaker's range $(\mathrm{H}-\mathrm{H} \%)$, RQs more frequently rise only to a mid-level, resulting in a plateau (H-L\%); see figure 6. Crucially, a distinction between rising and falling intonation is therefore insufficient also for polar questions. While it would be possible to model the contrast between polar ISQs and RQs on the basis of the phonological boundary tone alone ( $\mathrm{H} \%$ for ISQs vs $\mathrm{L} \%$ for RQs), or on the basis of the edge tone (H-H\% for ISQs vs $\mathrm{H}-\mathrm{L} \%$ for RQs), it is not possible to do so on the basis of the phrase accent alone (H- in both ISQs and RQs). If we complete the picture including assertions or statements, which have been argued to be semantically different from RQs (Caponigro \& Sprouse 2007; Biezma \& Rawlins 2017) and typically end in L-L\%, the edge tone (i.e., the combination of phrase accent and boundary tone) is essential. Hence, the distinction should be threefold: rise to a high level in the speaker's range $(\mathrm{H}-\mathrm{H} \%)$, rise to a mid-level plateau (H-L\%), and fall to a low level (L-L\%). Crucially in polar questions, $\mathrm{L} \%$ typically occurred in the combination $\mathrm{H}-\mathrm{L} \%$. In this sequence in English, L\% is not to be understood as the same low target as L\% in L-L\%. Due to the presence of $\mathrm{H}-$, it is an upstepped L\% (see section 1.1 above). It is lower 'than that of the upstepped H\% boundary tone' in H-H\% (Beckman \& Ayers 1997: 18), thus it is a mild rise or pitch plateau rather than a final fall. In terms of pitch height, $\mathrm{H}-\mathrm{L} \%$ is between $\mathrm{L}-\mathrm{L} \%$ and $\mathrm{H}-\mathrm{H} \%$. It almost seems as if $\mathrm{H}-\mathrm{L} \%$ is ideal to end an utterance that is interrogative in syntactic form (verb-first polar question), but whose answer is obvious and already part of the common ground (RQ). In other words, within polar questions, it is the upstepped rise vs the mid-level plateau, which distinguishes between ISQs and RQs. Crucially, this is very different from simply distinguishing between phrase-final rising and falling intonation.

Our results for edge tones go against Han (2002), who maintains that polar RQs are realised with a final fall due to their semantic similarity to assertions, as well as against Banuazizi \& Cresswell (1999), who suggest more falls for RQs due to the presence of obvious answers. Our generalisation is compatible with Pierrehumbert \& Hirschberg's (1990: 306) assumption that $\mathrm{H} \%$ in polar questions conveys cross-speaker 'forward reference', i.e. the speaker expects the interlocutor to take over the turn. Utterances ending in $\mathrm{L} \%$, on the other hand, do not convey this forward reference. Hedberg \& Sosa (2011) reserve $\mathrm{H} \%$ in polar questions for 'inquisitive' meaning, i.e. for utterances, for which 'the proposition it expresses allows for more than one way to update the common ground' 
(2011: 9). This is the case for regular ISQs, which, in our data, are overwhelmingly rising to $\mathrm{H}-\mathrm{H} \%$, but it is not true for RQs, all in line with Hedberg \& Sosa (2011). As Rohde (2006: 163 ) puts it, 'participants in a discourse understand rhetorical questions when they share sufficiently obvious and similar answers'. If this is the case, then the question is not inquisitive, thus does not demand $\mathrm{H} \%$. That the contour still does not fall to $\mathrm{L}-\mathrm{L} \%$ adds to the differences between RQs and statements, which also include their syntactic form, as well as the fact that RQs do, but statements do not allow for an answer, or at least not in the same way (Caponigro \& Sprouse 2007). This distinction is also in line with Biezma \& Rawlins (2017), who suggest that RQs and assertions differ such that '[w] here assertions are characteristically used to introduce a new commitment, RhQs are very well-suited for extracting commitments' (2017: 319). This threefold semantic distinction is reflected very well in the edge tone: inquisitive ISQs typically end in $\mathrm{H}-\mathrm{H}$ $\%$, RQs seeking to extract commitments typically end in H-L\% (i.e. a plateau), and assertions, which introduce new commitments, end in L-L\%.

Another important phonological cue to the difference between ISQs and RQs is the nuclear accent, still in line with hypothesis H1. While in wh-questions, it is the type of the nuclear accent on the object noun that plays a role (more $\mathrm{L}+\mathrm{H}^{*}$ in RQs than in ISQs, more $\mathrm{H}^{*}$ and ! $\mathrm{H}^{*}$ in ISQs than in RQs), in polar questions it is more the position of the nuclear accent. ${ }^{8}$ About a quarter of RQs had a nuclear $\mathrm{L}^{*}+\mathrm{H}$ accent on the subject anyone and no accent on the syntactic object, a pattern that was rare $(<5$ per cent) in ISQs, which typically had a nuclear accent on the object noun. So even if the nuclear accent placed on the subject in RQs cannot be called typical given that it only occurs in about a quarter of the cases, when it does occur, it is a safe indicator of rhetoricity, unless, of course, it is due to information structure (i.e. subject focus). Information structure, crucially, is a factor not relevant here because it was controlled for across the board. Regarding nuclear accent types, the differences between RQs and ISQs are less obvious in polar questions than in wh-questions. Across illocution types, the nuclear accent, if realised on the object noun, was typically $\mathrm{L}^{*}$. We assume that due to the role of the edge tone, which marks the difference between ISQs and RQs in polar questions but not in wh-questions, the role of the pitch accent is less crucial in polar questions than in wh-questions. However, in polar questions, nuclear accent position and edge tone may serve the function of conveying rhetorical meaning together. In particular, if the nuclear accent occurs early (i.e. on the subject anyone) and combines with the H-L\% edge tone, the duration of the tonal plateau increases, which may then strengthen its function.

In the prenuclear region, the results were not so striking, except that in polar questions we observed more unaccented verbs in ISQs than in RQs (although in general, the verb was mostly unaccented), and in wh-questions, the wh-pronoun typically received a bitonal $\mathrm{L}^{*}+\mathrm{H}$ pitch accent in RQs compared with a typical monotonal $\mathrm{H}^{*}$ accent in

${ }^{8}$ Recall from section 2.2 that the statistical effect of illocution type on $! \mathrm{H}^{*}$ merely approached significance, but becomes significant if the three speakers of varieties other than Western Canadian are removed from the analysis. 
ISQs (but there is no difference in frequency of accenting the $w h$-word). Even if the results are not as striking as for edge tones and nuclear accents, the fact that differences can be found between illocution types ties in with previous work on the role of the prenuclear region. In the present context, the $w h$-word in $w h$-ISQs represents the unspecified part of the proposition, i.e. the speaker requests information to fill the open slot and $\mathrm{s} / \mathrm{he}$ therefore marks the wh-word with $\mathrm{H}^{*}$. In RQs, on the other hand, the wh-word corresponds to the obvious answer, rather than the unknown one. The speakers prefer prenuclear $\mathrm{L}^{*}+\mathrm{H}$ in this case. Remember from section 1.1.1 Hedberg \& Sosa's (2002) finding that the prenuclear accent on the $w h$-word is, in their data, typically $\mathrm{L}^{*+\mathrm{H}}$. In our data, $\mathrm{L}^{*+\mathrm{H}}$ occurs in both ISQs and RQs, but it is more frequent in RQs, with more monotonal $\mathrm{H}^{*}$ accents in ISQs.

Evaluating hypothesis H2, we find that RQs and ISQs indeed differ in the realisation of the phonetic parameters. The most robust parameter is duration: we found longer durations in RQs than in ISQs in both question types. Specifically, this generally concerns the object as well as the $w h$-words in $w h$-questions and subject nouns in polar questions. These findings are in line with work on German RQs (Braun et al. 2018), which found longer constituent durations in RQs than in ISQs, and more generally with findings that questions are produced with shorter durations (faster speaking rate) than declaratives (Niebuhr et al. 2010; Heuven \& Zanten 2005). Assuming that RQs have an assertive feel rather than inquisitive semantics, and given that declaratives also exhibit longer durations than genuine questions, our duration results for RQs vs ISQs are exactly what would be predicted.

Differences in voice quality were found only for the $w h$-word in $w h$-questions, but not for polar questions. The $w h$-word was breathier in RQs than in ISQs. This is reminiscent of the results of Braun et al. (2018) for German RQs, which show that a higher proportion of words were realised with breathy voice in RQs than in ISQs. Note that this result goes against Niebuhr et al.'s (2010) findings for declarative questions and declarative statements in German, where questions were realised with breathier voice quality than statements.

Regarding initial pitch, in wh-questions there was no difference between illocution types in the number of utterances that started with high initial pitch (in the top 10 per cent of the speakers pitch range) and no difference in the mean $\mathrm{f0}$ of the first word. This goes against the generalisation by Sicoli et al. (2015), who report higher initial pitch in evaluative questions (including RQs). In polar questions, there were indeed significantly more RQs than ISQs with high initial pitch on the subject anyone. However, this effect disappeared in the analysis of the mean $\mathrm{f0}$ of the first word. The partial overlap and differences in comparison with Sicoli et al.'s data suggest that other factors besides speaker attitude and illocution type may play a role (e.g. syntactic structure, turn position, and utterance length, which were not controlled for in Sicoli et al. 2015). Furthermore, the measure they used for initial pitch is naturally strongly affected by accent type. This latter point also holds for our analysis of initial pitch. Remember that in wh-questions, the prenuclear accent on who distinguishes between 
illocution types (monotonal $\mathrm{H}^{*}$ in ISQs vs rising $\mathrm{L}^{*+\mathrm{H}}$ in RQs), thus the mean pitch will naturally differ between the two.

In sum, our results clearly show that in production, the meaning differences between ISQs and RQs are reflected in the prosodic realisation chosen by the speaker. The speaker situates the question in the given situational context and produces it with corresponding prosody. We have thus confirmed the assumption made in the literature that prosody can be (and is) used to signal illocutionary force. However, while some of the literature is speculative (e.g. Han's 2002 claim that polar RQs must be realised with a final fall) or vague (e.g. Biezma \& Rawlins' 2017: 306, 313 statement that the prosodic characteristics of RQs are 'hard to pin down'), we identify specific phonological and phonetic cues, which predict with some certainty whether a syntactically ambiguous interrogative utterance is intended as an ISQ or RQ.

Given our results, we would like to emphasise the following points. First, when modelling the interface between prosody and meaning, it is essential to consider not just the boundary tone or edge tone, but pitch accents and their distribution, too. In previous literature, especially in theoretical literature and work using introspective data (Bartels 1999; Han 2002), the focus has been on the terminus. The way this has been done - concentrating on the difference between falls and rises - is insufficient for at least two reasons. One is that the edge tone is not always distinctive. The present study has shown that wh-questions end in L-L\% regardless of illocution type. Another reason is that an intonational terminus can be shaped in more than just two ways (rise, fall). In particular, the present study has shown that we need a third category (the plateau) to fully capture the differences between illocution types.

The second point we would like to emphasise is that it is important not just to consider intonation. Our results, as well as previous results on different utterance types in the literature (see section 1.2 above), show that phonetic parameters contribute to the distinction between illocution types. Most strongly, this has been shown for duration, at least in production. Future experiments will have to deal with cue weighting: which is the strongest cue? For example, does phonology (e.g. pitch accent types) outweigh duration, or is it the other way around? If duration were manipulated to signal the contrast between illocution types, would that be enough? How strong is prosody in comparison to the context, or, to put it differently, if the context demands a rhetorical interpretation of an interrogative, will prosody be able to override this? These questions cannot be pursued in the present article. The merits of the present article are at least twofold: first, to the best of our knowledge it is the first study that systematically compares the prosody of English string-identical ISQs and RQs in production, using a controlled production experiment. Second, we demonstrate that to provide a complete picture of the prosody of illocution types it is not enough to consider a single parameter or even phonology only. Moreover, we identify the phonological and phonetic parameters that do play a role. As a result, the prosodic parameters which distinguish between RQs and ISQs are not 'hard to pin down' (Biezma \& Rawlins 2017: 306, 313) anymore. 
Authors' address:

Fachbereich Sprachwissenschaft

Universität Konstanz

Fach 186

78457 Konstanz

Germany

nicole.dehe@uni-konstanz.de

bettina.braun@uni-konstanz.de

\section{References}

Banuazizi, Atissa \& Cassandre Cresswell. 1999. Is that a real question? Final rises, final falls, and discourse function in yes-no question intonation. In Sabrina J. Billings, John P. Boyle \& Aaron M. Griffith (eds.), CLS 35-1: Papers from the main session, 1-13. Chicago: Chicago Linguistic Society.

Bartels, Christine. 1999. The intonation of English statements and questions: A compositional interpretation. New York and London: Garland.

Beckman, Mary E. \& Elam Ayers. 1997. Guidelines for ToBI labelling, version 3. Columbus, OH: The Ohio State University Research Foundation.

Beckman, Mary E. \& Julia Hirschberg. N.d. The ToBI annotation conventions. www.ling.ohiostate.edu/ tobi/ame tobi/annotation conventions.html

Beckman, Mary E., Julia Hirschberg \& Stefanie Shattuck-Hufnagel. 2005. The original ToBI system and the evolution of the ToBI framework. In Sun-Ah Jun (ed.), Prosodic typology, 9-54. Oxford: Oxford University Press.

Benjamini, Yoav \& Yosef Hochberg. 1995. Controlling the false discovery rate: A practical and powerful approach to multiple testing. Journal of the Royal Statistical Society, Series B 57, 289-300.

Biezma, María \& Kyle Rawlins. 2012. Responding to alternative and polar questions. Linguistics and Philosophy 35(5), 361-406.

Biezma, María \& Kyle Rawlins. 2017. Rhetorical questions: Severing asking from questioning. In Dan Burgdorf, Jacob Collard, Sireemas Maspong \& Brynhildur Stefánsdóttir (eds.), Proceedings of the 27th Semantics and Linguistic Theory (SALT 27) conference, 302-22.

Boersma, Paul \& David Weenink. 2018. Praat: Doing phonetics by computer [computer program]. www.praat.org

Braun, Bettina, Nicole Dehé, Jana Neitsch, Daniela Wochner \& Katharina Zahner. 2018. The prosody of rhetorical and information-seeking questions in German. Language and Speech. https://doi.org/10.1177/0023830918816351

Caponigro, Ivano \& John Sprouse. 2007. Rhetorical questions as questions. In Estela Puig Waldmüller (ed.), Proceedings of Sinn und Bedeutung 11, 121-33. Barcelona: Universitat Pompeu Fabra.

Dehé, Nicole, Bettina Braun \& Daniela Wochner. 2018. The prosody of rhetorical vs informationseeking questions in Icelandic. In Proceedings of Speech Prosody, 9th International Conference (2018), 13-16 June 2018, Poznan, Poland, 403-7. doi: 10.21437/SpeechProsody.2018-82

DiCanio, Christian. 2009. The phonetics of register in Takhian Thong Chong. Journal of the International Phonetic Association 39(2), 162-88.

Grice, Martine \& Stefan Baumann. 2002. Deutsche Intonation und GToBI. Linguistische Berichte 191, 267-98. 
Grice, Martine, Stefan Baumann \& Ralf Benzmüller. 2005. German intonation in autosegmental-metrical phonology. In Sun-Ah Jun (ed.), Prosodic typology: The phonology of intonation and phrasing, 55-83. Oxford: Oxford University Press.

Groenendijk, Jeroen A. G. \& Martin J. B. Stokhof. 1984. Studies on the semantics of questions and the pragmatics of answers. $\mathrm{PhD}$ dissertation, University of Amsterdam.

Gussenhoven, Carlos. 2016. Analysis of intonation: The case of MAE_ToBI. Laboratory Phonology 7(1), 1-35.

Gutiérrez Rexach, Javier. 1998. Rhetorical questions, relevance and scales. Revista Alicantina de Estudios Ingleses 11, 139-55.

Hamblin, Charles L. 1973. Questions in Montague English. Foundations of Language 10(1), 41-53.

Han, Chung-Hye. 2002. Interpreting interrogatives as rhetorical questions. Lingua 112(3), 201-29.

Hausser, Roland \& Dietmar Zaefferer. 1979. Questions and answers in a context-dependent Montague Grammar. In Franz Guenthner \& Siegfried J. Schmidt, Formal semantics and pragmatics for natural languages, 339-58. Dordrecht: Reidel.

Hedberg, Nancy \& Juan M. Sosa. 2002. The prosody of questions in natural discourse. In Proceedings of Speech Prosody 2002, International Conference, Aix-en-Provence, France, April 11-13, 2002, 375-8. ISCA Archive: www.isca-speech.org/archive/sp2002

Hedberg, Nancy \& Juan M. Sosa. 2011. A unified account of the meaning of English questions with non-canonical intonation. Paper presented at the International Seminar on Prosodic Interfaces, Jawaharlal Nehru University, New Delhi, India.

Hedberg, Nancy, Juan M. Sosa \& Lorna Fadden. 2004. Meanings and configurations of questions in English. In Bernard Bel \& Isabelle Marlien (eds.), Proceedings of Speech Prosody 2004, International Conference; Nara, Japan, March 23-26, 2004, 309-12. ISCA Archive: www.iscaspeech.org/archive/sp2004

Hedberg, Nancy, Juan M. Sosa \& Emrah Görgülü. 2017. The meaning of intonation in yes-no questions in American English: A corpus study. Corpus Linguistics and Linguistic Theory 13(2), 321-68.

Hedberg, Nancy, Juan M. Sosa, Emrah Gürgülü \& Morgan Mameni. 2010. Prosody and pragmatics of wh-interrogatives. In Melinda Heijl (ed.), Proceedings of the 2010 annual conference of the Canadian Linguistic Association. http://homes.chass.utoronto.ca/ cla-acl/ actes2010/actes2010.html

Heuven, Vincent J. van, Judith Haan \& Robert S. Kirsner. 1999. Phonetic correlates of sentence type in Dutch: Statement, question and command. In ETRWon Dialogue and Prosody (Diapro), September 1-3, 1999, Veldhoven, The Netherlands, 35-40. ISCA Archive: www.isca-speech. org/archive_open/dia_pros

Heuven, Vincent J. van \& E. van Zanten. 2005. Speech rate as a secondary prosodic characteristic of polarity questions in three languages. Speech Communication 47(1-2), 87-99.

Hudson, Richard A. 1975. The meaning of questions. Language 51(1), 1-31.

Ilie, Cornelia. 1995. The validity of rhetorical questions as arguments in the courtroom. Paper presented to the Special Fields and Cases. In Frans H. van Eemeren (ed.), Proceedings of the Third ISSA Conference on Argumentation, 73-88. Amsterdam: International Centre for the Study of Argumentation.

Karttunen, Lauri. 1977. Syntax and semantics of questions. Linguistics and Philosophy 1(1), 3-44.

Krifka, Manfred. 2011. Questions. In Klaus von Heusinger, Claudia Maienborn \& Paul Portner (eds.), Semantics: An international handbook of natural language meaning, vol. 2, 1742-85. Berlin: Mouton de Gruyter.

Ladd, D. Robert. 2008. Intonational phonology. Cambridge: Cambridge University Press.

Landis, J. Richard \& Gary G. Koch. 1977. The measurement of observer agreement for categorical data. Biometrics 33(1), 159-74. 
Mooshammer, Christine. 2010. Acoustic and laryngographic measures of the laryngeal reflexes of linguistic prominence and vocal effort in German. Journal of Acoustic Society of America 127(2), 1047-58.

Niebuhr, Oliver. 2013. The acoustic complexity of intonation. In Eva Liina Asu-Garcia \& Pärtel Lippus (eds.), Nordic Prosody: Proceedings of the XIth conference, Tartu 2012. Frankfurt: Peter Lang.

Niebuhr, Oliver, Julia Bergherr, Susanne Huth, Cassandra Lill \& Jessica Neuschulz. 2010. Intonationsfragen hinterfragt! Die Vielschichtigkeit der prosodischen Unterschiede zwischen Aussage- und Fragestäzen mit deklarative Syntax [On the complexity of prosodic differences between declaratives and declarative questions]. Zeitschrift für Dialektologie und Linguistik 77(3), 304-46.

Petrone, Caterina \& Oliver Niebuhr. 2014. On the intonation of German intonation questions: The role of the prenuclear region. Language and Speech 57(1), 108-46.

Pierrehumbert, Janet B. \& Julia Hirschberg. 1990. The meaning of intonational contours in the interpretation of discourse. In Philip R. Cohen, Jerry Morgan \& Martha E. Pollack (eds.), Intentions in communication, 271-311. Cambridge, MA: MIT Press.

Quirk, Randolph, Sidney Greenbaum, Geoffrey Leech \& Jan Svartvik (eds.). 1985. A comprehensive grammar of the English language. New York: Longman.

Rialland, Annie. 2009. The African lax question prosody: Its realization and geographical distribution. Lingua 119(6), 928-49.

Rohde, Hannah. 2006. Rhetorical questions as redundant interrogatives. San Diego Linguistic Papers 2, 134-68.

Sadock, Jerrold. 1971. Queclaratives. In Papers from the 7th regional meeting of the Chicago Linguistics Society, 223-31.

Schourup, Lawrence C. 1985. Common discourse particles in English conversation. London: Routledge.

Schubiger, Maria. 1958. English intonation: Its form and function Tübingen: Max Niemeyer.

Sicoli, Mark A., Tanya Stivers, Nick J. Enfield \& Stephen C. Levinson. 2015. Marked initial pitch in questions signals marked communicative function. Language and Speech 58(2), 204-23.

Silverman, Kim E., Mary Beckman, John F. Pitrelli, Mari Ostendorf, Colin Wrightman, Patti Price, Janet B. Pierrehumbert \& Julia Hirschberg. 1992. ToBI: A standard for labeling English prosody. In Proceedings of the 1992 International Conference on Spoken Language Processing, 12-16 October, Banff, 867-70.

Von Stechow, Arnim \& Thomas Ede Zimmermann. 1984. Term answers and contextual change. Linguistics 22(1), 3-40.

Wilson, Deidre \& Dan Sperber. 1988. Mood and the analysis of non-declarative sentences. In Jonathan Dancy, J. M. E. Moravcsik \& C. C. W. Taylor (eds.), Human agency: Language, duty and value, 77-101. Stanford, CA: Stanford University Press. 